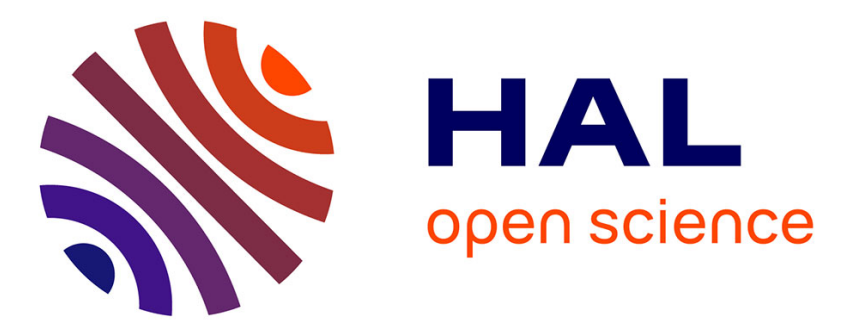

\title{
Evidence for carbonyl sulfide (OCS) conversion to CO in the lower atmosphere of Venus
}

\author{
Yuk L. Yung, M. C. Liang, X. Jiang, R. L. Shia, C. Lee, B. Bézard, \\ Emmanuel Marcq
}

\section{> To cite this version:}

Yuk L. Yung, M. C. Liang, X. Jiang, R. L. Shia, C. Lee, et al.. Evidence for carbonyl sulfide (OCS) conversion to CO in the lower atmosphere of Venus. Journal of Geophysical Research. Planets, 2009, 114 (E5), 10.1029/2008JE003094 . insu-03161448

\section{HAL Id: insu-03161448 \\ https://hal-insu.archives-ouvertes.fr/insu-03161448}

Submitted on 6 Mar 2021

HAL is a multi-disciplinary open access archive for the deposit and dissemination of scientific research documents, whether they are published or not. The documents may come from teaching and research institutions in France or abroad, or from public or private research centers.
L'archive ouverte pluridisciplinaire HAL, est destinée au dépôt et à la diffusion de documents scientifiques de niveau recherche, publiés ou non, émanant des établissements d'enseignement et de recherche français ou étrangers, des laboratoires publics ou privés. 


\title{
Evidence for carbonyl sulfide (OCS) conversion to $\mathrm{CO}$ in the lower atmosphere of Venus
}

\author{
Yuk L. Yung, ${ }^{1}$ M. C. Liang, ${ }^{2,3}$ X. Jiang, ${ }^{4}$ R. L. Shia, ${ }^{1}$ C. Lee, ${ }^{1}$ B. Bézard, ${ }^{5}$ and E. Marcq ${ }^{5}$ \\ Received 31 January 2008; revised 30 December 2008; accepted 9 January 2009; published 26 March 2009.
}

[1] The chemical regimes in the atmosphere of Venus vary from photochemistry in the middle atmosphere to thermal equilibrium chemistry in the lower atmosphere and the surface. Many chemical cycles have been proposed, but few details about these cycles are fully verified by comparison between observations and modeling. Recent high-quality data of carbonyl sulfide (OCS) and CO from ground-based and Venus Express observations provide a unique opportunity to test our understanding of chemistry and transport in the lower atmosphere of Venus. The spatial distributions of OCS and CO in the atmosphere reflect a sensitive balance between chemistry and transport. On the basis of our updated photochemical model and winds from Lee et al.'s (2007) general circulation model, we study the chemistry and transport in a simplified two-dimensional chemistry-transport model. OCS is produced by heterogeneous reactions on the surface; the middle atmosphere is a net sink for OCS. The combination of data and modeling provides strong evidence for the loss of OCS by conversion to CO. The detailed chemical mechanism is currently unknown, although a number of speculations have been proposed. The sensitivity of the distributions of OCS and CO to model parameters is reported.

Citation: Yung, Y. L., M. C. Liang, X. Jiang, R. L. Shia, C. Lee, B. Bézard, and E. Marcq (2009), Evidence for carbonyl sulfide (OCS) conversion to CO in the lower atmosphere of Venus, J. Geophys. Res., 114, E00B34, doi:10.1029/2008JE003094.

\section{Introduction}

[2] Sulfur chemistry is critical to the composition of the Venus atmosphere, and four sulfur species have been firmly identified: $\mathrm{SO}_{2}, \mathrm{SO}, \mathrm{OCS}$, and $\mathrm{H}_{2} \mathrm{SO}_{4}$ (vapor and aerosol). Mills et al. [2007] have recently carried out an extensive review of chemistry in the atmosphere of Venus, and the reader is referred to this paper for a summary of previous results. As noted in this review, there are two parts to the chemistry of sulfur species in the atmosphere of Venus. On the surface of Venus (and possibly in the dense, hot lower atmosphere) the chemistry is dominated by thermodynamic equilibrium chemistry [Fegley et al., 1997]. Near and above the cloud tops, the chemistry is driven by solar UV radiation. Thus, the partitioning of sulfur among the different species represents a competition between thermodynamic equilibrium chemistry at the surface and in the lower atmosphere and photochemistry in the middle atmosphere. This underscores the importance of transport and mixing in

\footnotetext{
${ }^{1}$ Division of Geological and Planetary Sciences, California Institute of Technology, Pasadena, California, USA.

${ }^{2}$ Research Center for Environmental Changes, Academia Sinica, Taipei, Taiwan.

${ }^{3}$ Graduate Institute of Astronomy, National Central University, Jhongli, Taiwan.

${ }^{4}$ Department of Earth and Atmospheric Sciences, University of Houston, Houston, Texas, USA.

${ }^{5}$ LESIA, Observatoire de Paris, Meudon, France.

Copyright 2009 by the American Geophysical Union. 0148-0227/09/2008JE003094
}

determining the distribution of chemical species in the atmosphere of Venus.

[3] Early works on sulfur chemistry on Venus by Prinn $[1975,1978,1979]$ is based on a prediction by Lewis [1970] of sulfur species with mixing ratios of $60 \mathrm{ppmv}$ for OCS, 6 ppmv for $\mathrm{H}_{2} \mathrm{~S}$, and 0.3 ppmv for $\mathrm{SO}_{2}$. Prinn [1975] suggested a scheme of photochemical formation of sulfuric acid and polysulfur from carbonyl sulfide OCS.

[4] The primary sulfur carrier from the deep atmosphere and surface to the middle atmosphere is OCS. Near and above the cloud tops, OCS readily dissociates, releasing the $\mathrm{S}$ atom.

$$
\mathrm{OCS}+\mathrm{h} \nu \rightarrow \mathrm{CO}+\mathrm{S}\left({ }^{1} \mathrm{D}\right)
$$

where $S\left({ }^{1} \mathrm{D}\right)$ is the first electronically excited state of the $\mathrm{S}$ atom and is $1.145 \mathrm{eV}$ above the ground $\mathrm{S}\left({ }^{3} \mathrm{P}\right)$ state. The most likely fate of $\mathrm{S}\left({ }^{1} \mathrm{D}\right)$ is quenching:

$$
\mathrm{S}\left({ }^{1} \mathrm{D}\right)+\mathrm{CO}_{2} \rightarrow \mathrm{CO}_{2}+\mathrm{S}\left({ }^{3} \mathrm{P}\right)
$$

The other branch of (2) forming $\mathrm{CO}+\mathrm{SO}$ is endothermic. If there is a source of oxygen atoms (such as photodissociation of $\mathrm{CO}_{2}$ ), $\mathrm{S}$ undergoes oxidation to $\mathrm{SO}_{2}$, which subsequently forms $\mathrm{SO}_{3}$ and $\mathrm{H}_{2} \mathrm{SO}_{4}$ and condenses to form the cloud layers as follows.

[5] The $\mathrm{S}$ atom gets oxidized to $\mathrm{SO}$ by reacting with $\mathrm{O}$ and $\mathrm{O}_{2}$

$$
\begin{gathered}
\mathrm{S}+\mathrm{O}+\mathrm{M} \rightarrow \mathrm{SO}+\mathrm{M} \\
\mathrm{S}+\mathrm{O}_{2} \rightarrow \mathrm{SO}+\mathrm{O}
\end{gathered}
$$


Table 1. Mixing Ratios of $\mathrm{CO}_{2}$ and Trace Gases at the Lower Boundary of $58 \mathrm{~km}$

\begin{tabular}{lcc}
\hline Species & Mixing Ratio & Reference \\
\hline $\mathrm{CO}_{2}$ & 0.965 & Yung and DeMore [1982] \\
$\mathrm{H}_{2} \mathrm{O}$ & $2.6 \times 10^{-5}$ & Mills et al. [2007], Bertaux et al. [2007] \\
$\mathrm{CO}$ & $3.0 \times 10^{-5}$ & Yung and DeMore [1982] \\
$\mathrm{HCl}$ & $4.0 \times 10^{-7}$ & Yung and DeMore [1982] \\
$\mathrm{SO}_{2}$ & $1.3 \times 10^{-4}$ & Mills et al. [2007], Bézard et al. [1993] \\
$\mathrm{OCS}$ & $3.0 \times 10^{-7}$ & Krasnopolsky [2008], this work \\
\hline
\end{tabular}

Further oxidation to $\mathrm{SO}_{2}$ can proceed via the three-body reaction

$$
\mathrm{SO}+\mathrm{O}+\mathrm{M} \rightarrow \mathrm{SO}_{2}+\mathrm{M}
$$

Catalytic oxidation by $\mathrm{ClO}$ is also possible

$$
\mathrm{SO}+\mathrm{ClO} \rightarrow \mathrm{SO}_{2}+\mathrm{Cl}
$$

The rate for reaction (6) has been measured in laboratory studies [Sander et al., 2006], and reaction (6) accounts for $10-20 \%$ of the loss of SO at $66-80 \mathrm{~km}$ altitude in recent photochemical models [Pernice et al., 2004; Mills and Allen, 2007]. Note that the net result is the oxidation of $\mathrm{S}$ to $\mathrm{SO}_{2}$, and eventually to $\mathrm{H}_{2} \mathrm{SO}_{4}$.

[6] The above scenario dominates primarily above the cloud tops (located at $\sim 60 \mathrm{~km}$ above the surface). Below the cloud tops, oxygen is scarce. In the absence of an oxygen source, $\mathrm{S}$ reacts with other $\mathrm{S}$ bearing species to form polysulfur, $S_{x}$. $S$ atoms can react to produce $S_{2}$ or $S_{2}$ may be produced via coupled $\mathrm{S}-\mathrm{Cl}$ chemistry involving chlorosulfanes [Mills and Allen, 2007]. Production of $\mathrm{S}_{3}$ is possible through successive addition reactions. $\mathrm{S}_{3}$ is the chemical analog of ozone, known as thiozone. As the number of sulfur atoms increases, the polyatomic sulfur compounds tend to have lower-saturation vapor pressures. It is convenient to name all sulfur species beyond $\mathrm{S}_{3}$ "polysulfur" or $\mathrm{S}_{\mathrm{x}}$. The production of $\mathrm{S}_{\mathrm{x}}$ is part of what has been termed the "slow atmospheric sulfur cycle" [von Zahn et al., 1983], which is completed by decomposition reactions in the lower atmosphere. In the UV region $S_{x}$ absorbs strongly, and it may be the principal constituent of the unidentified UV absorber in the upper atmosphere of Venus [Toon et al., 1982]. Krasnopolsky and Pollack [1994] and Krasnopolsky [2007] presented detailed models of OCS and $\mathrm{S}_{\mathrm{x}}$ chemistry. However, critical components of their chemical model are not based on known laboratory kinetics.

[7] Therefore, the large picture is that OCS is produced at the surface, transported to the middle atmosphere, where it is destroyed by photolysis above the cloud tops. However, between 1 and 10 bars $(\sim 30$ to $\sim 50 \mathrm{~km})$, there may be an additional sink, whose identity is currently unknown and which is a major focus of this paper. The compelling observational evidences are (1) vertical gradient of OCS between 30 and $50 \mathrm{~km}$, (2) latitudinal gradient of OCS in this region, and (3) complementary latitudinal gradient in $\mathrm{CO}$, suggesting OCS to $\mathrm{CO}$ conversion.

[8] In this paper, we report a combined study of photochemistry and transport in a two-dimensional (2-D) chemistrytransport model (CTM) for the atmosphere of Venus, with emphasis on carbonyl sulfide (OCS) and carbon monoxide (CO). Section 2 describes the mechanistic aspects of this work, consisting of three key components: (1) an updated $1-\mathrm{D}$ photochemical model above the cloud tops, (2) a 2-D transport model based on winds and diffusivities derived from a general circulation model (GCM), and (3) a simplified chemical model for OCS and $\mathrm{CO}$ for the entire atmosphere. The main modeling results for OCS and CO, along with comparisons with recent observations, and model sensitivity are discussed in section 3 . Section 4 examines the implications of the model, especially on the nature of the unidentified sink reaction for OCS. More speculative results are discussed in Appendix A. The conclusions are stated in section 5 .

\section{Photochemistry and Transport}

\subsection{1-D Photochemical Model}

[9] The UV radiation is averaged diurnally before photolytic calculations, and the latitude dependence is carefully taken into account (see Liang et al. [2005] and references contained therein for a detailed description of the model.) The 1-D model [Yung and DeMore, 1982; Mills et al., 2007] is from 58 to $112 \mathrm{~km}$. The vertical eddy mixing coefficients equal those obtained previously [Yung and DeMore, 1982]. Additional UV attenuation caused by absorbers estimated by Crisp [1986] is included. The chemical scheme used in this paper is taken from Mills et al. [2007]. The volume mixing ratios of $\mathrm{CO}_{2}, \mathrm{H}_{2} \mathrm{O}, \mathrm{CO}, \mathrm{HCl}, \mathrm{SO}_{2}$, and $\mathrm{OCS}$ at the lower boundary are given in Table 1 . For the other species, free escape through the lower boundary is allowed. The upper boundary is closed for all species.

[10] Figure 1 shows the mixing ratios of $\mathrm{CO}_{2}$ and the most abundant trace gases in the model. The abundance of $\mathrm{CO}$ increases with height because there is a source of $\mathrm{CO}$ from photolysis of $\mathrm{CO}_{2}$ and OCS higher up. $\mathrm{CO}$ is removed by catalytic chemistry involving $\mathrm{Cl}$ radicals derived from $\mathrm{HCl}$ photolysis, which results in a decline of $\mathrm{HCl}$ with altitude. Both $\mathrm{SO}_{2}$ and $\mathrm{H}_{2} \mathrm{O}$ are removed by the formation of $\mathrm{H}_{2} \mathrm{SO}_{4}$. As $\mathrm{H}_{2} \mathrm{SO}_{4}$ aerosols are removed from the model, they represent a net sink of $\mathrm{SO}_{2}$ and $\mathrm{H}_{2} \mathrm{O}$, thereby explaining their rapid decrease with altitude. OCS is destroyed by photolysis above the cloud tops. The secondary peak around $85 \mathrm{~km}$ is caused by the reaction

$$
\mathrm{S}+\mathrm{ClCO} \rightarrow \mathrm{OCS}+\mathrm{Cl}
$$

with the $\mathrm{S}$ atom ultimately derived from

$$
\begin{gathered}
\mathrm{SO}_{2}+\mathrm{h} \nu \rightarrow \mathrm{SO}+\mathrm{O} \\
\mathrm{SO}+\mathrm{h} \nu \rightarrow \mathrm{S}+\mathrm{O}
\end{gathered}
$$

Figure 2 shows the mixing ratios of $\mathrm{O}, \mathrm{O}_{2}$, and $\mathrm{O}_{3}$. The mesosphere is a net source of oxygen from $\mathrm{CO}_{2}$ photolysis. Oxygen is rapidly consumed by catalytic recombination with $\mathrm{CO}$ and oxidation of $\mathrm{SO}_{2}$ to $\mathrm{SO}_{3}$, followed by formation of $\mathrm{H}_{2} \mathrm{SO}_{4}$. The latter is removed from the model.

[11] Figure 3 presents the mixing ratios of major hydrogen species. $\mathrm{H}_{2} \mathrm{O}$ is the major carrier of hydrogen to the 


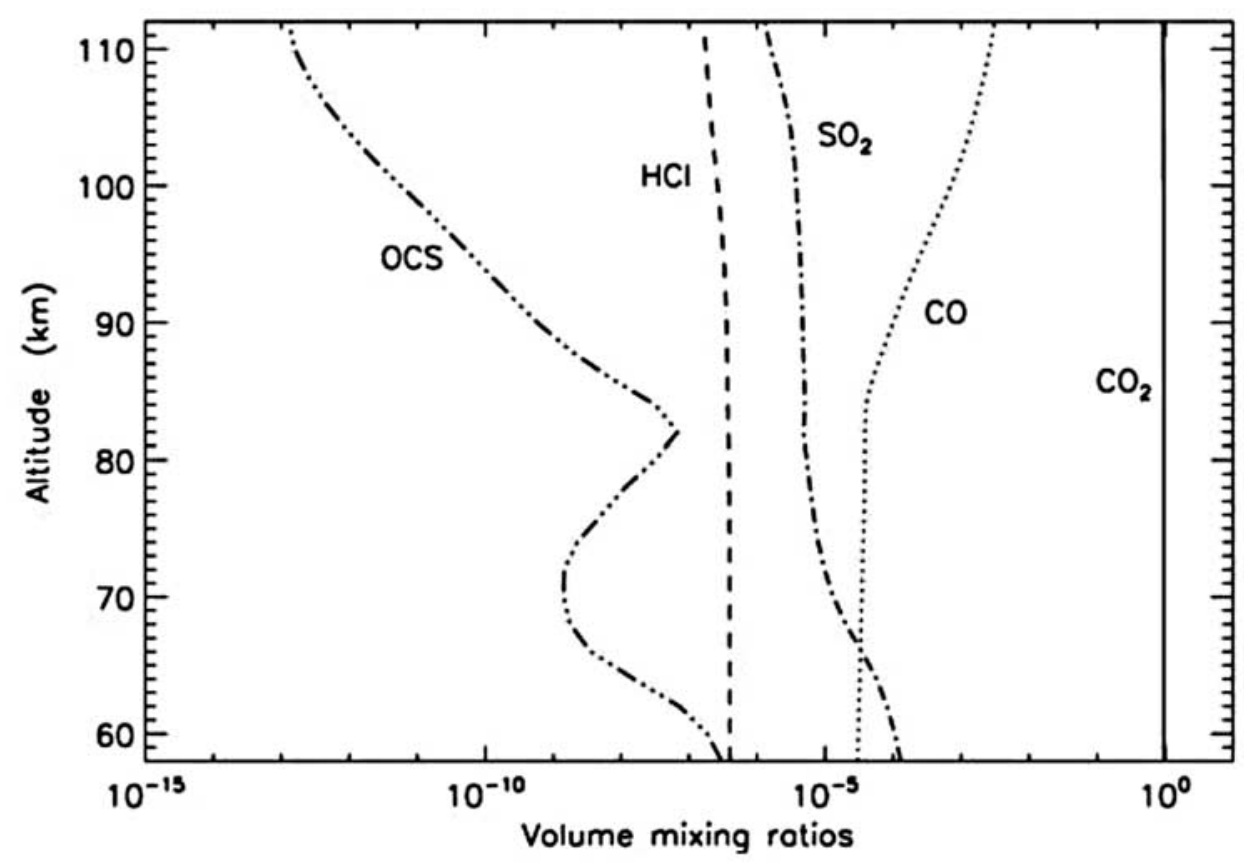

Figure 1. Vertical profiles of mixing ratios of $\mathrm{CO}_{2}, \mathrm{CO}, \mathrm{HCl}, \mathrm{SO}_{2}$, and OCS predicted by the 1-D photochemical model. The boundary conditions are summarized in Table 1.

middle atmosphere above the cloud tops. Photolysis of $\mathrm{H}_{2} \mathrm{O}$ produces $\mathrm{H}_{2}$ and radicals $\mathrm{H}, \mathrm{OH}, \mathrm{HO}_{2}$, and $\mathrm{H}_{2} \mathrm{O}_{2}$ (odd hydrogen). The odd hydrogen species play a minor role in the photochemistry of Venus. Reactive chlorine bearing radicals are shown in Figure 4. They are derived from $\mathrm{HCl}$ photolysis, which also contributes to the production of odd hydrogen. The chlorine bearing species play a major role in the stability of the $\mathrm{CO}_{2}$ atmosphere [Yung and
DeMore, 1982]. There is a possible coupling to sulfur chemistry but the kinetics is highly uncertain [Mills and Allen, 2007].

[12] The possibility of $S_{x}$ formation is illustrated in Figure 5. The principal sources of $\mathrm{S}$ are photolysis of OCS and SO. In the absence of $\mathrm{O}_{2}$, formation of higher polymers of sulfur is possible. The column production rates are summarized in Table 2. The $\mathrm{S}_{\mathrm{n}}$ species are in photo-

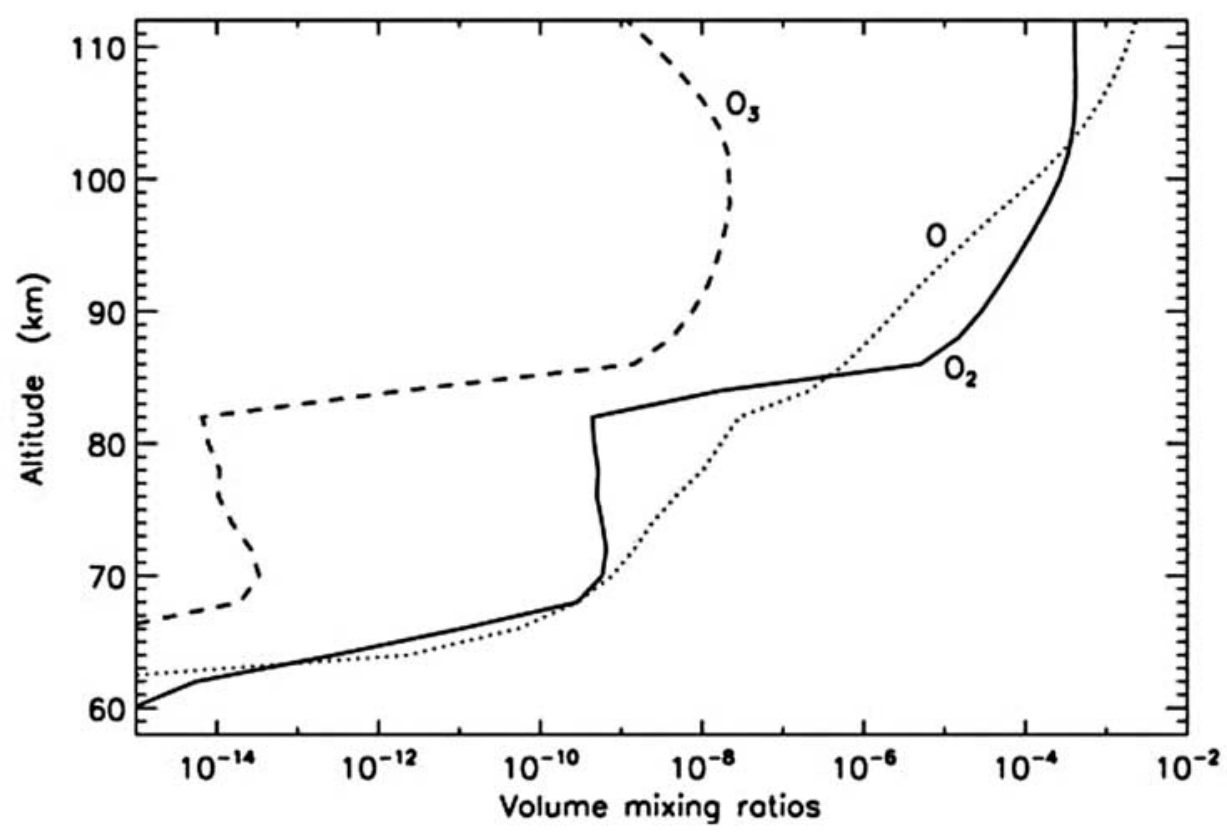

Figure 2. Same as Figure 1 for oxygen-bearing molecules, $\mathrm{O}_{2}, \mathrm{O}$, and $\mathrm{O}_{3}$. 


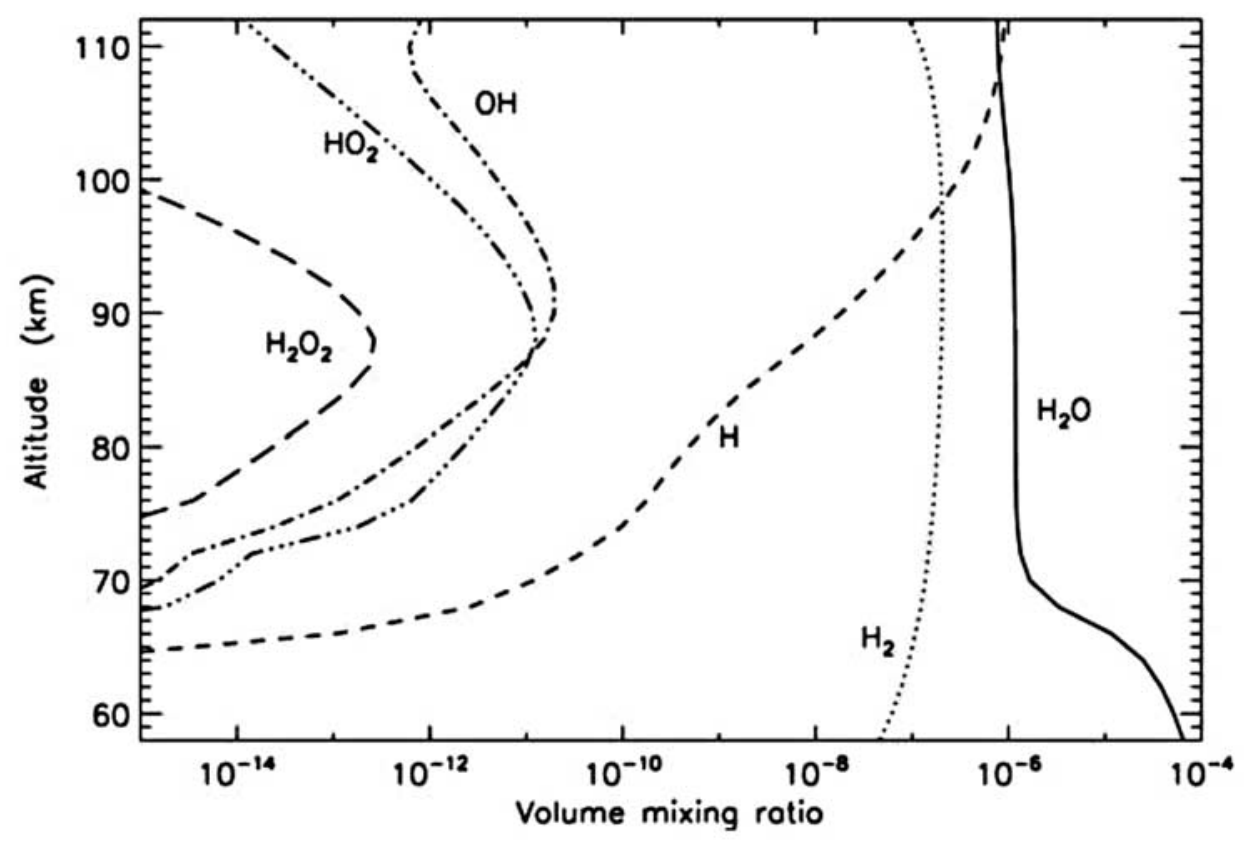

Figure 3. Same as Figure 1 for hydrogen-bearing molecules, $\mathrm{H}_{2} \mathrm{O}, \mathrm{H}_{2}, \mathrm{H}, \mathrm{OH}, \mathrm{HO}_{2}$, and $\mathrm{H}_{2} \mathrm{O}_{2}$.

chemical equilibrium; that is, production and loss (primarily by photolysis) are equal, except for $\mathrm{S}_{8}$. The model stops at $\mathrm{S}_{8}$, which is removed from the atmosphere in the model. The possible role of this chemistry in the lower atmosphere is discussed in Appendix A.

[13] The 1-D photochemical model with full chemistry provides the basis for constructing a simplified chemical model for OCS and CO for the 2-D chemistry-transport model. This will be taken up in section 2.3.

\subsection{Transport Model}

[14] The general circulation model (GCM) used to calculate the stream function uses the dynamical core of the Hadley Centre general circulation model [Cullen, 1993] with a $5^{\circ}$ horizontal grid staggered as an Arakawa B grid [Arakawa and Lamb, 1977] from pole to pole and a 31-level hybrid sigma pressure vertical coordinate from surface to about $100 \mathrm{~km}$. Forcing and dissipation are provided by linear parameterizations of the radiative forcing (cooling to space) and boundary layer (Rayleigh friction). A qualita-

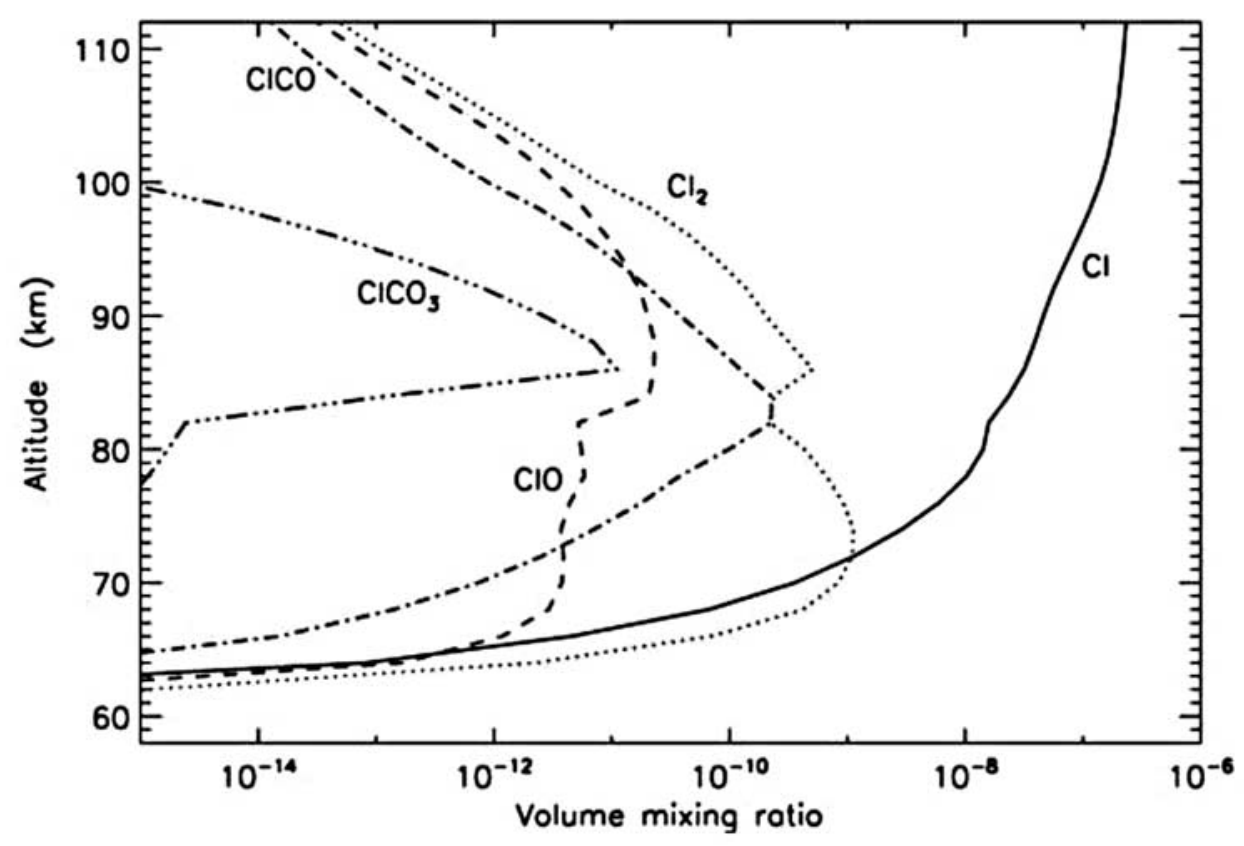

Figure 4. Same as Figure 1 for chlorine-bearing molecules, $\mathrm{Cl}, \mathrm{Cl}_{2}, \mathrm{ClO}, \mathrm{ClCO}$, and $\mathrm{ClCO}_{3}$. 


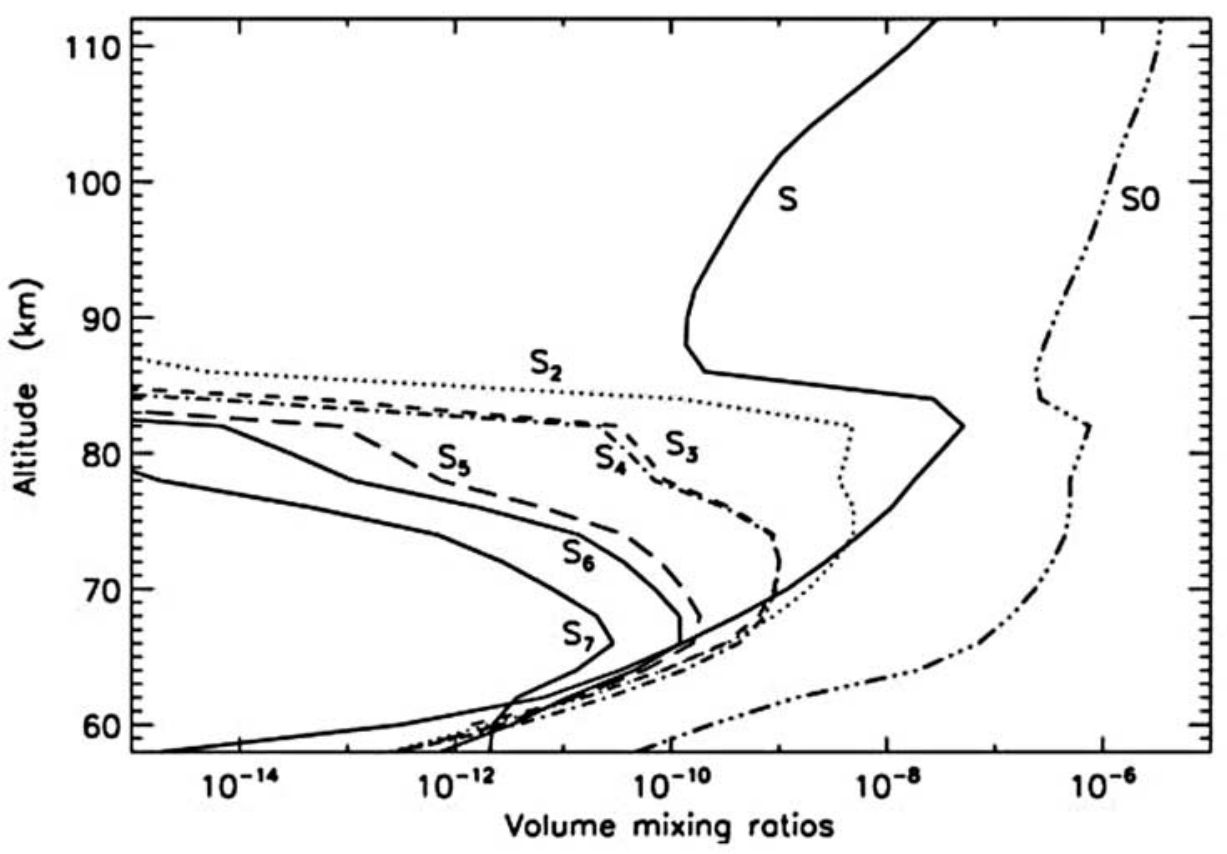

Figure 5. Same as Figure 1 sulfur-bearing molecules, $\mathrm{SO}, \mathrm{S}, \mathrm{S}_{2}, \mathrm{~S}_{3}, \mathrm{~S}_{4}, \mathrm{~S}_{5}, \mathrm{~S}_{6}$, and $\mathrm{S}_{7}$.

tively realistic radiative forcing is used to drive an equatorial superrotation and low wave number planetary waves in the middle atmosphere. No topography or diurnal cycle is used, and no active chemical processes are considered within the GCM. We briefly summarize below the essential parts of the model and make a comparison with other model results available in the literature. Full details of the GCM and this experiment are given by Lee et al. [2007].

[15] When a similar radiative forcing is used, the circulation produced by other GCMs [Yamamoto and Takahashi, 2003; Hollingsworth et al., 2007; Herrnstein and Dowling, 2007] is at least as strong as the circulation produced by Lee et al.'s [2007] GCM shown here, suggesting the circulation is not unreasonable for the radiative forcing used. When a radiative forcing with less heating in the lower atmosphere is used [e.g., Hollingsworth et al., 2007] the circulation in the lower atmosphere is much weaker, but the superrotation is also much weaker and does not compare well to the observed Venus atmosphere. However, the middle atmosphere circulation still resembles a Hadley-like overturning.

[16] Observations by Venus Express [Limaye, 2007] and Pioneer Venus [Schubert, 1983] suggest that the circulation, at least at cloud level, is stronger than in the GCM shown here. However, there are few observations at depth, making the calculations in the deep atmosphere somewhat speculative. These results suggest that the "age of air" calculation shown here (see later discussion) should be more accurate in the middle atmosphere than in the lower atmosphere, but physical and observational constraints suggests even the lower atmosphere values presented should be within an order of magnitude of the actual values.

[17] The meridional circulation is calculated from wind and temperature from GCM [Lee et al., 2007]. The data from the GCM are in $5^{\circ} \times 5^{\circ}$ latitude-longitude resolution. It has 31 vertical levels from 92 bar to $10^{-3}$ bar. We choose the same method as that of Jiang et al. [2004] to calculate the transformed meridional circulation for the Venus. First, the three-dimensional (3-D) meridional mass flux, $\psi_{P}(\lambda, \varphi, p)$, is determined by

$$
\psi_{P}(\lambda, \varphi, p)=\frac{2 \pi a \cos \varphi}{g} \int_{o}^{p} V\left(\lambda, \varphi, p^{\prime}\right) d p^{\prime}
$$

where $a$ is the Venus radius, $\lambda, \varphi$, and $p$ are the longitude, latitude and pressure, $V$ is the meridional velocity, and $g$ is the gravitational acceleration rate. Then we interpolate the 3-D meridional mass flux to isentropic surfaces, using a mass-conserving linear interpolation scheme [Juckes et al., 1994]. The 2-D isentropic mass stream function, $\psi_{\theta}(\varphi, \theta)$, is derived by zonal averaging of the $3-\mathrm{D}$ isentropic meridional mass flux, $\psi_{\theta}(\lambda, \varphi, \theta)$, along isentropes. Finally, we interpolate the 2-D isentropic mass stream function, $\psi_{\theta}(\varphi, \theta)$, to pressure coordinates and scale by the density to produce the pressure surface stream function, $\psi_{P}$ $(\varphi, p)$, which is used to drive the 2-D CTM. The resulting pressure surface meridional circulation, $\psi_{P}(\varphi, p)$, shown in Figure 6 (left), is like that for the Hadley cell in the

Table 2. Column Production Rates of Sulfur Species Above the Cloud Tops $^{\mathrm{a}}$

\begin{tabular}{ccc}
\hline Species & Principal Reactions & Column Rate \\
\hline $\mathrm{S}$ & $\mathrm{SO}+\mathrm{h} \nu, \mathrm{S}_{2}+\mathrm{O}$ & $8.2 \times 10^{11}$ \\
$\mathrm{~S}_{2}$ & $\mathrm{~S}+\mathrm{S}+\mathrm{M}, \mathrm{S}+\mathrm{OCS}$ & $2.4 \times 10^{11}$ \\
$\mathrm{~S}_{3}$ & $\mathrm{~S}+\mathrm{S}_{2}+\mathrm{M}$ & $1.6 \times 10^{10}$ \\
$\mathrm{~S}_{4}$ & $\mathrm{~S}_{2}+\mathrm{S}_{2}+\mathrm{M}$ & $2.7 \times 10^{10}$ \\
$\mathrm{~S}_{5}$ & $\mathrm{~S}+\mathrm{S}_{4}+\mathrm{M}$ & $7.3 \times 10^{9}$ \\
$\mathrm{~S}_{6}$ & $\mathrm{~S}+\mathrm{S}_{5}+\mathrm{M}, \mathrm{S}_{3}+\mathrm{S}_{3}+\mathrm{M}$ & $6.1 \times 10^{9}$ \\
$\mathrm{~S}_{7}$ & $\mathrm{~S}+\mathrm{S}_{6}+\mathrm{M}$ & $1.6 \times 10^{9}$ \\
$\mathrm{~S}_{8}$ & $\mathrm{~S}_{4}+\mathrm{S}_{4}+\mathrm{M}, \mathrm{S}_{2}+\mathrm{S}_{6}+\mathrm{M}$ & $5.2 \times 10^{9}$ \\
\hline
\end{tabular}

${ }^{\mathrm{a}} \mathrm{S}_{\mathrm{n}}$, sulfur species. Units are in molecules $\mathrm{cm}^{-2} \mathrm{~s}^{-1}$. The principal source of $S_{n}$ is COS photolysis, whose column rate is $7.5 \times 10^{10}$ molecules $\mathrm{cm}^{-2} \mathrm{~s}^{-1}$. At higher altitudes, SO photolysis provides an additional source of $\mathrm{S}$ atoms. 


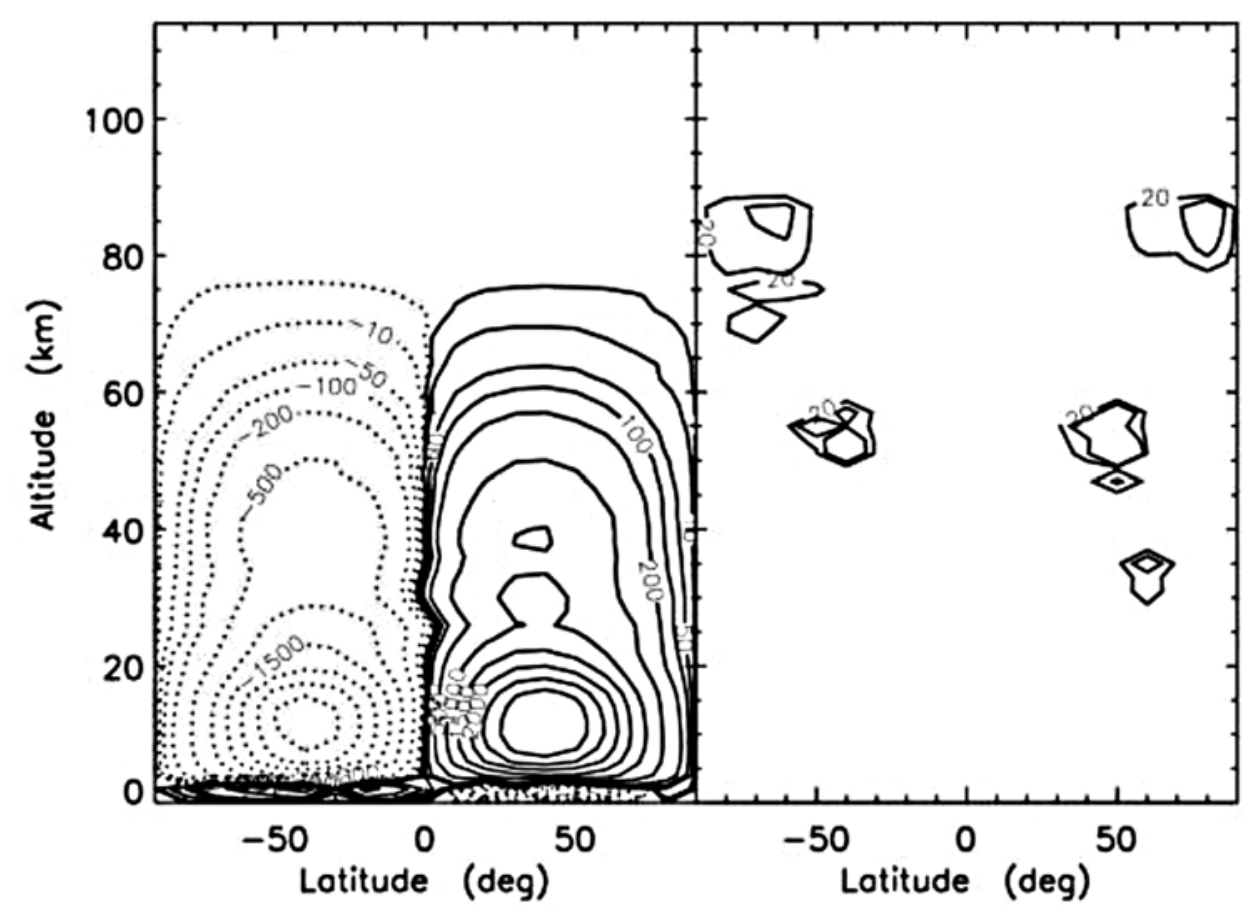

Figure 6. (left) Mass stream function $\psi$ and (right) horizontal eddy mixing coefficient $K_{y y}$ calculated from Lee et al. [2007]. Units are $10^{9} \mathrm{~kg} \mathrm{~s}^{-1}$ for $\psi$ and $10^{9} \mathrm{~cm}^{2} \mathrm{~s}^{-1}$ for $K_{y y}$. Minimum $K_{y y}$ is set to be $10^{10} \mathrm{~cm}^{2} \mathrm{~s}^{-1}$, a value that is chosen to be large enough that small-scale transport (resulting from the derivation of $\psi$ ) is reduced but small enough that the transport remains dominated by $\psi$.

terrestrial atmosphere. There is upwelling in the tropics, followed by downwelling in the high latitudes. The total mass flux is $\sim 3000 \times 10^{9} \mathrm{~kg} \mathrm{~s}^{-1}$, a value that should be compared to the terrestrial value of $\sim 200 \times 10^{9} \mathrm{~kg} \mathrm{~s}^{-1}$ [see Peixoto and Oort, 1992, Figure 7.19]. Since the atmosphere of Venus is about 100 times more massive than the terrestrial atmosphere, this implies that the atmosphere turns over in about a decade, as the Earth's atmosphere turns over in a year. This result is consistent with the age of air experiment described later. Note that the latitudinal extension of the circulation is much greater than that for the terrestrial atmosphere owing to the near absence of the Coriolis effect.

[18] The horizontal mixing coefficients, $K_{y y}$ is calculated on the isentropic surfaces Jiang et al. [2004, equation (2)]. Then we interpolate it from the isentropic surfaces to the pressure surfaces for use in the 2-D CTM. Figure 6 (right) shows a latitude-altitude profile of $K_{y y}$. The values for $K_{y y}$ are larger in the midlatitudes than the tropics owing to the presence of enhanced wave activities in the midlatitudes. Although the transport in the atmosphere is dominated by advection, the effect of horizontal diffusion is non trivial in smoothing out gradients in chemical tracers.

[19] To visualize the effect of the circulation on transport of chemical species in the atmosphere, we compute the age of air, a quantity that has proved to be extremely useful in understanding the stratosphere-troposphere exchange in the terrestrial atmosphere [Hall and Waugh, 1997]. The age of air is obtained by following the trend of an inert tracer, whose abundance at the surface increases linearly with time. Figure 7 shows the age of air in the lower atmosphere of Venus derived from the circulation shown in Figure 6. It takes about 10 (Earth) years for an air parcel released at the surface to reach the middle atmosphere at the cloud tops. Since the radiative forcing does not include a diurnal cycle, the GCM does not simulate the large temperature variations seen above $90 \mathrm{~km}$ [Bertaux et al., 2007] associated with the variation in radiative forcing. As a result the age of air is only approximate in the upper atmosphere.

[20] There is a simple physical interpretation of the mass stream function [see Shia et al., 1989, equation (12)]: $\psi_{P}$ $(\varphi, p)$ is the integral from latitude $=-90$ to $\varphi$ for the vertical mass flux across the pressure $=p$ level, or the integral from the surface to pressure $=p$ for the horizontal mass flux across the latitude $=\varphi$. The convention is positive for upward and northward flows. For later reference, it is convenient to divide the atmosphere into nine boxes, as shown in Figure 8. Using the values of the stream function from Figure 6 (left) and the formulas by Shia et al. [1989], we derive the appropriate mass fluxes in and out of each box in units of $10^{9} \mathrm{~kg} \mathrm{~s}^{-1}$. The numbers have been rounded off, and so the values are approximate. Note that the divergence of fluxes from each box is zero owing to conservation of mass. As we will show later, the central box is crucial for our investigation of the OCS and $\mathrm{CO}$ budget. This simple diagram will allow us to make a qualitative estimate of the chemical production and loss rates of OCS and $\mathrm{CO}$ in this region of the atmosphere from observed gradients in the concentrations of the tracers.

\subsection{2-D Chemistry-Transport Model With Simplified Chemistry}

[21] The 2-D Caltech/JPL photochemical model has been employed to simulate the meridional distribution of hydro- 


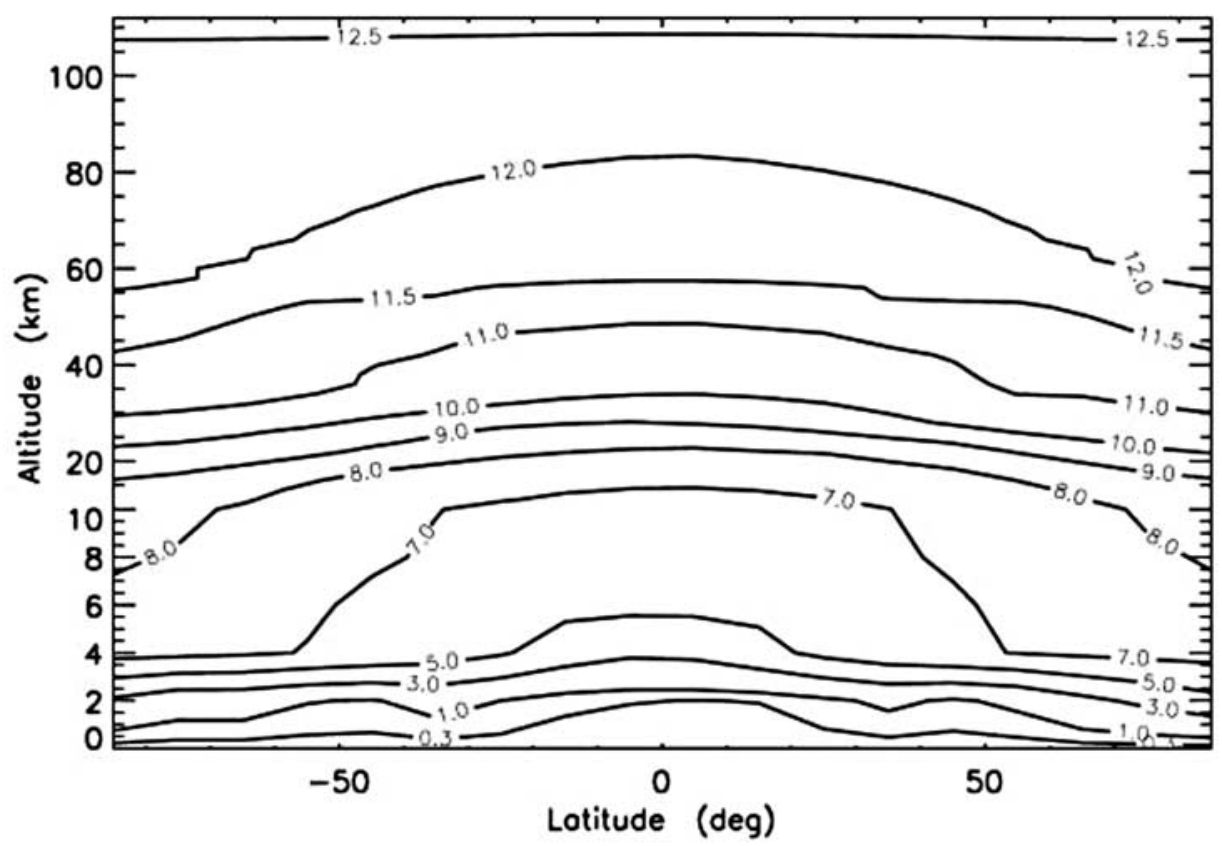

Figure 7. Age of air (Earth year) derived from the circulation shown in Figure 6.

carbons in the atmosphere of Jupiter [Liang et al., 2005] and the isotopic composition of ozone in the terrestrial atmosphere [Liang and Yung, 2007]. In principle, such 2-D models are similar to that used for Titan [Lebonnois et al., 2001] and have been useful in modeling the interaction of chemistry and transport in planetary atmospheres. As noted earlier, we obtain our transport component of the model from a GCM.

[22] We extend the base model [Yung and DeMore, 1982; Mills et al., 2007], which sets the lower boundary at the

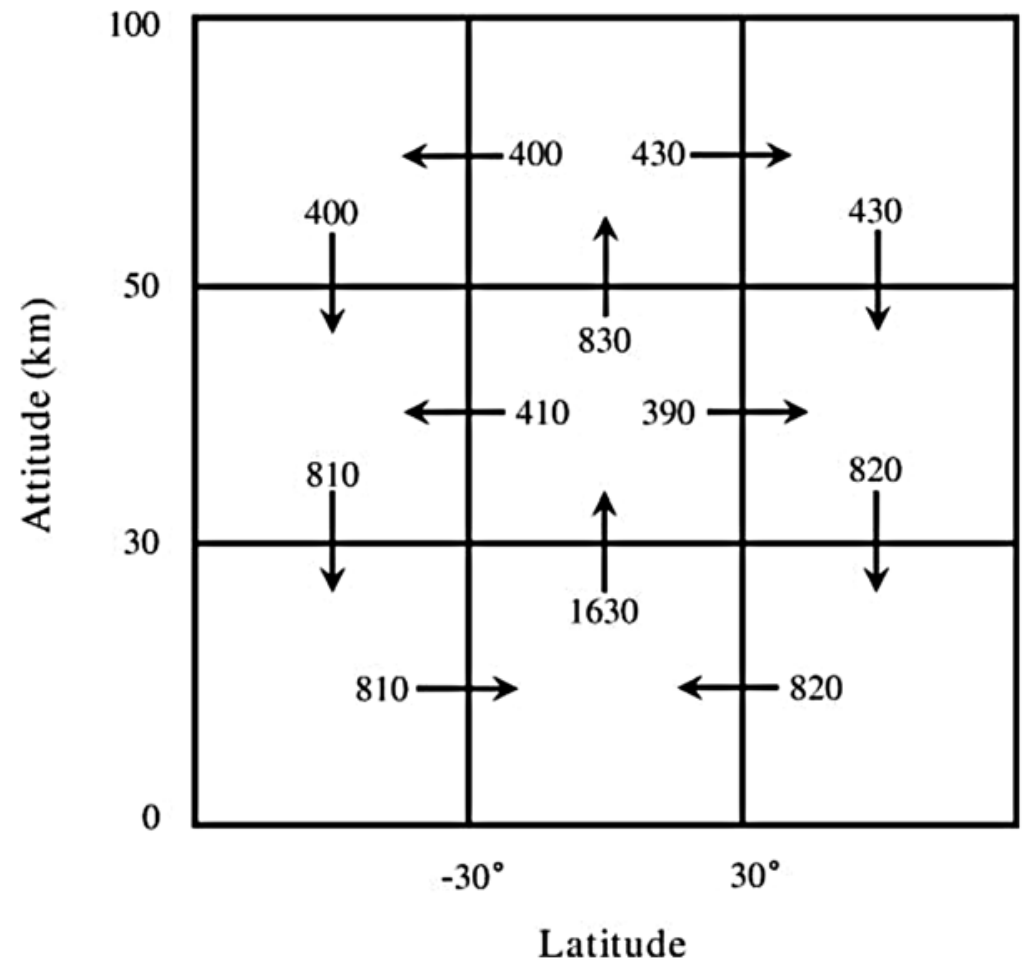

Figure 8. Mass fluxes in units of $10^{9} \mathrm{~kg} \mathrm{~s}^{-1}$ across the boundaries of nine boxes in the atmosphere of Venus. The boundaries at the bottom, top, and sides are impermeable. The numbers are taken and rounded off from Figure 6. 


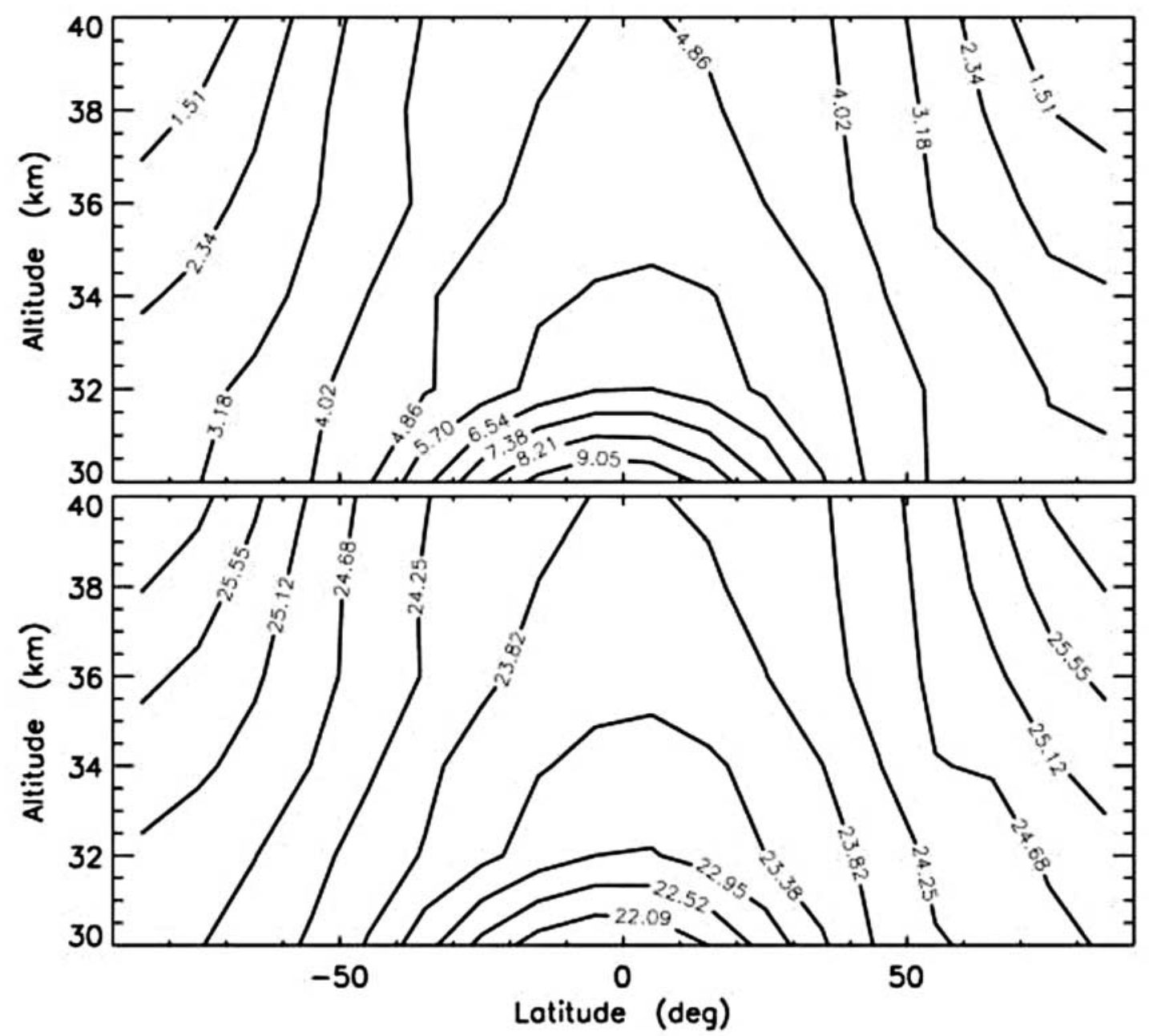

Figure 9. Model profiles of (top) OCS and (bottom) CO, in units of ppmv, using the model that includes reaction (R11). See text.

cloud tops, to the entire atmosphere from 0 to $112 \mathrm{~km}$. Above the planetary boundary $(\sim 2 \mathrm{~km})$, the vertical eddy mixing coefficients are uniformly set at $\sim 100 \mathrm{~cm}^{2} \mathrm{~s}^{-1}$ and we assume that the transport in this region is dominated by the advection. In the planetary boundary, the vertical eddy coefficients are set at $\sim 10^{4} \mathrm{~cm}^{2} \mathrm{~s}^{-1}$, a value high enough simulating for the mixings/transport of matters between the troposphere and the boundary, where the mixing ratios of OCS and $\mathrm{CO}$ are set to be 23 and 16.6 ppmv, respectively. Since we are primarily interested in the chemistry of OCS and CO the lower atmosphere, the chemistry in the atmosphere above the cloud tops only serves as the upper boundary and may be greatly simplified. Thus, the chemical model is reduced to about 10 key reactions involving production and destruction of OCS and CO. Similar simplification has been carried out for the chemistry of ozone in the Earth's atmosphere [Liang et al., 2006]. In order to successfully simulate the distribution of OCS and CO in the lower atmosphere, we have to postulate a loss reaction for converting OCS to $\mathrm{CO}$ via reaction with $\mathrm{X}$ :

$$
\mathrm{OCS}+\mathrm{X} \rightarrow \mathrm{CO}+\mathrm{Y}
$$

If we assume that $\mathrm{R} 11$ is a bimolecular reaction, then the loss coefficient is given by

$$
\mathrm{L}_{11}=\mathrm{k}_{11} \times[\mathrm{X}]
$$

where $\mathrm{k}_{11}$ is the bimolecular rate coefficient [see Yung and DeMore, 1999, chapter 3]. By trial and error, we found that $\mathrm{L}_{11} \sim 10^{-8} \mathrm{~s}^{-1}$ in the region around $30 \mathrm{~km}$. We will discuss the chemical and physical mechanisms for this additional sink for OCS later. The identity of $\mathrm{X}$ in (12) remains elusive. Candidate molecules include $\mathrm{SO}_{3},(\mathrm{SO})_{2}$ and $\mathrm{S}$.

\section{Model Results}

\subsection{Modeling Results and Comparison With Observations}

[23] Figure 9 shows the latitude-altitude plots of OCS and $\mathrm{CO}$ in the region from 30 to $40 \mathrm{~km}$. The vertical distribution of OCS is consistent with its source at the surface, transport to the middle atmosphere, where it is destroyed. The falloff of OCS with altitude is not as large as the observed value. This may be due to inadequacy in the transport model or 


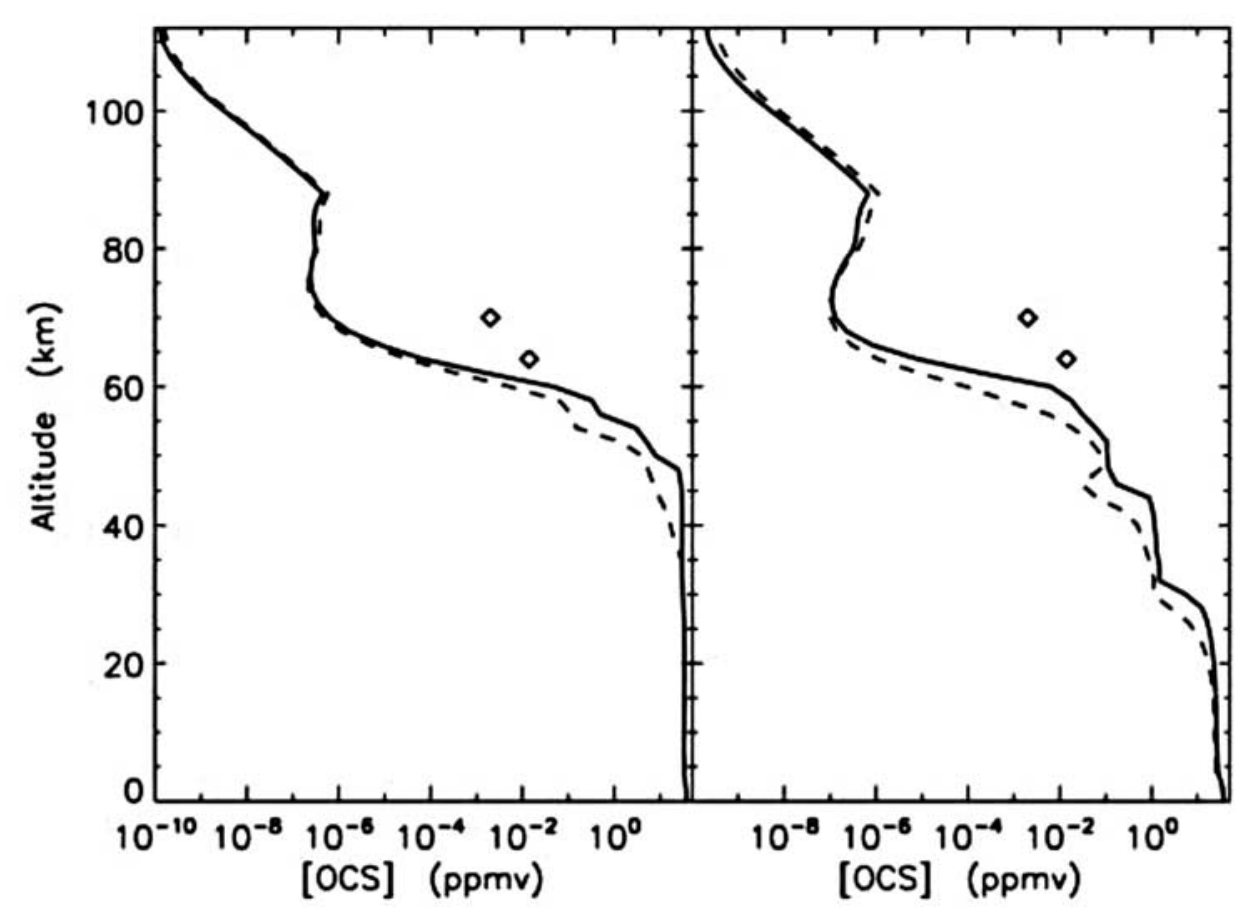

Figure 10. Vertical profiles of OCS computed by the 2-D model: global mean (solid curves) and at $65^{\circ} \mathrm{N}$ (dashed curves). (left) Loss by photolysis of OCS alone. (right) Additional sink (R11) is included. See text.

loss rate. According to the schematic in Figure 8, the export of OCS poor air from the tropics and via the downward portion of the Hadley cell results in lower OCS mixing ratios at middle and high latitudes. The pattern of $\mathrm{CO}$ is similar to that for OCS, except that the gradients are now reversed. In this case, there is a source of $\mathrm{CO}$ from the mesosphere and an additional source from reaction (R11). Comparison between model predictions and observations will be discussed as follows.

[24] Figure 10 (left) shows the vertical profiles of OCS from our model with loss only by photolysis. Although the model correctly simulates the falloff of OCS above the cloud tops, the scale height of the OCS density at $30 \mathrm{~km}$ is close to the atmospheric scale height of $\sim 10 \mathrm{~km}$ (i.e., small vertical gradient in mixing ratio), in contradiction to the observed scale height of about $2 \mathrm{~km}$ (see below). The reason is that the photolysis coefficient of OCS falls rapidly below the cloud tops. In order to produce the correct scale height of OCS at $30 \mathrm{~km}$, we include an additional parameterized sink for OCS in the model. The results are shown in Figure 10 (right) and are in agreement with the observations.

[25] The falloff of the OCS profile around $30 \mathrm{~km}$ is a well-documented observation [see Marcq et al., 2005, 2006, and references therein]. The slope is

$$
\mathrm{d} \log [\mathrm{OCS}] / \mathrm{d} \log \mathrm{P}=5 \pm 1
$$

where $\mathrm{P}$ is pressure. The corresponding scale height at this altitude is about $2 \mathrm{~km}$. Higher up in the atmosphere, above $60 \mathrm{~km}$, the OCS concentrations are in fair agreement with recent measurements by Krasnopolsky [2008]. The poorer agreement at $70 \mathrm{~km}$ may be due to the unrealistic circulation above the cloud tops.

[26] The latitudinal distribution of OCS at $33 \mathrm{~km}$ from our model is presented in Figure 11 (top). The Venus Express VIRTIS (asterisks) and ground-based telescope IRTF (diamonds) are shown by special symbols. Dotted curve represents the cosine function of latitude. The model is in satisfactory agreement with the data. The reasons for the increase in the mixing ratio of OCS away from the tropics were discussed earlier. The error bars are 1- $\sigma$ standard deviation intervals, for both VIRTIS and IRTF retrievals.

[27] We assume that the variation of OCS at the probed altitude $(33 \mathrm{~km})$ was caused by vertical translations of the reference profile given by Pollack et al. [1993]. A more detailed discussion of the considered set of OCS vertical profiles is available in the work by Marcq et al. [2005, 2008]. Orbits 98, 110, 111, 134, 136, 258, and 277 of the Venus Express spectra, have been used, mostly in science case 2 (off-pericenter observations), because of the need of long integration times. The spectra were provided by the high spectral resolution IR channel from the VIRTIS instrument (VIRTIS-H). The resolving power $\mathrm{R}$ in the used order of dispersion (order 5) is close to 1500 between 2.42 and $2.46 \mu \mathrm{m}$. The interpretation of these spectra is still in progress, so the retrievals in upcoming publications may differ significantly, although the main trends should persist at least qualitatively. On the other hand, the Earth-based retrievals have already been published by Marcq et al. [2005, 2006]. The used spectra were acquired on 13 August 2004 using the order 3 of the SpeX spectrometer $(\mathrm{R} \sim 2000$ 

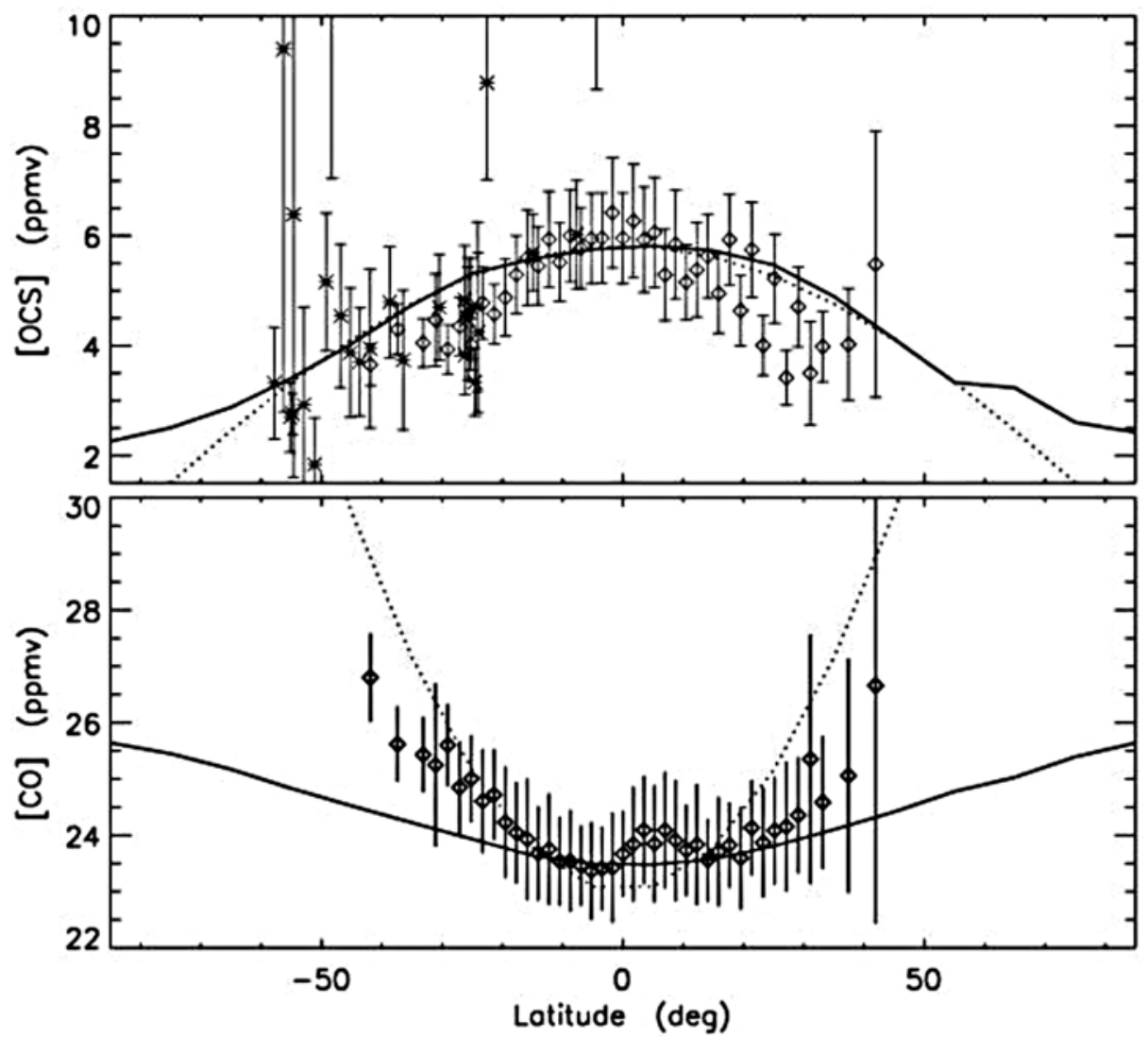

Figure 11. (top) Model OCS distribution at $33 \mathrm{~km}$ (solid curve). The Venus Express (asterisks) and ground-based telescope IRTF (diamonds) are shown by symbols. Dotted curve represents the cosine function of latitude. (bottom) Similar results for CO.

from $1.92 \mu \mathrm{m}$ to $2.48 \mu \mathrm{m}$, which includes the whole $2.3 \mu \mathrm{m}$ spectral window) at the NASA IRTF. Only the retrievals from slit positions 1 and 2, as defined by Marcq et al. [2006, Figure 1], are used.

[28] Figure 11 (bottom) shows the model latitudinal distribution of $\mathrm{CO}$ at $36 \mathrm{~km}$. The latitudinal structure of $\mathrm{CO}$ is the complement of that of OCS in Figure 11 (top). This gives rise to the hypothesis that the chemical destruction of OCS leads to the production of $\mathrm{CO}$, as suggested by reaction $(\mathrm{R} 11)$. We will return to this issue later.

\subsection{Sensitivity of Model to Input Parameters}

[29] The agreement between the model and data shown in Figure 11 is far from perfect. It is important to investigate the model sensitivity of these results to input parameters. The most important input to the model is the stream function that is responsible for advection in the model. We note that the model profile of OCS in Figure 11 is flatter than the data; this is true also for CO (see Figure 11). One way we can enhance the curvature of the chemical species is to fine-tune the stream function and $K_{y y}$ and the chemical reaction rates. There are many ways to modify the parameters in the model. After many trials, we conclude that the latitudinal gradients in OCS and $\mathrm{CO}$ are sharpened by (1) narrowing the width and increasing the amplitude of the Hadley cell, (2) enhancing the unidentified chemistry R11, and (3) reducing horizontal diffusion.
[30] The modifications of the standard model are summarized in Table 3. Model A is same as the standard model, except that the peak of the stream function is modified by the following factors. We have nine latitude boxes evenly spaced between south pole (SP) and equator (EQ). Let the stream function at box $i$ be multiplied by a factor $f_{i}$, where $\mathrm{i}=1$ is the SP box at $-85^{\circ}$ and $\mathrm{i}=9$ is the EQ box at $-5^{\circ}$. In model $A$, we set $f_{6}=2$, allowing it to fall back linearly to 1 at SP and EQ. The changes in the northern hemisphere, for $\mathrm{i}=10$ to 18 , are a mirror image of those in

Table 3. Sensitivity of Latitudinal Gradients in OCS and CO at $30 \mathrm{~km}$ to Model Parameters ${ }^{\mathrm{a}}$

\begin{tabular}{lccc}
\hline Model & $\begin{array}{c}\Delta[\mathrm{OCS}] \\
(\mathrm{ppmv})\end{array}$ & $\begin{array}{c}\Delta[\mathrm{CO}] \\
(\mathrm{ppmv})\end{array}$ & Parameter Change \\
\hline Standard & 1.65 & -1.51 & $\psi_{\text {mid }} \times 2$ \\
$\mathrm{~A}$ & 1.83 & -1.84 & $\psi_{\text {mid }} \times 3$ \\
$\mathrm{~B}$ & 1.77 & -1.88 & Same as B, R11 $\times 3$ \\
$\mathrm{C}$ & 2.15 & -1.57 & Same as C, $\psi_{\text {mid }} \times 3+\psi_{\text {trop }} \times 2$ \\
$\mathrm{D}$ & 2.24 & -1.78 & Same as D, $K_{y y} / 4$ \\
$\mathrm{E}$ & 2.63 & -2.50 & Same as D, $K_{y y} / 10$ \\
$\mathrm{~F}$ & 2.80 & -3.00 & Same as Standard, R11 $11=0$ \\
$\mathrm{G}$ & 1.22 & -1.08 &
\end{tabular}

${ }^{\mathrm{a}} \Delta[\mathrm{OCS}]=[\mathrm{OCS}]\left(0^{\circ}\right)-[\mathrm{OCS}]\left(-60^{\circ}\right) ; \Delta[\mathrm{CO}]=[\mathrm{CO}]\left(0^{\circ}\right)-[\mathrm{CO}]\left(-60^{\circ}\right)$ The atmosphere is divided into three vertical regions (see Figure 8). Stream functions in the middle and bottom regions of the atmosphere are $\psi_{\text {mid }}$ and $\psi_{\text {trop }}$, respectively. 


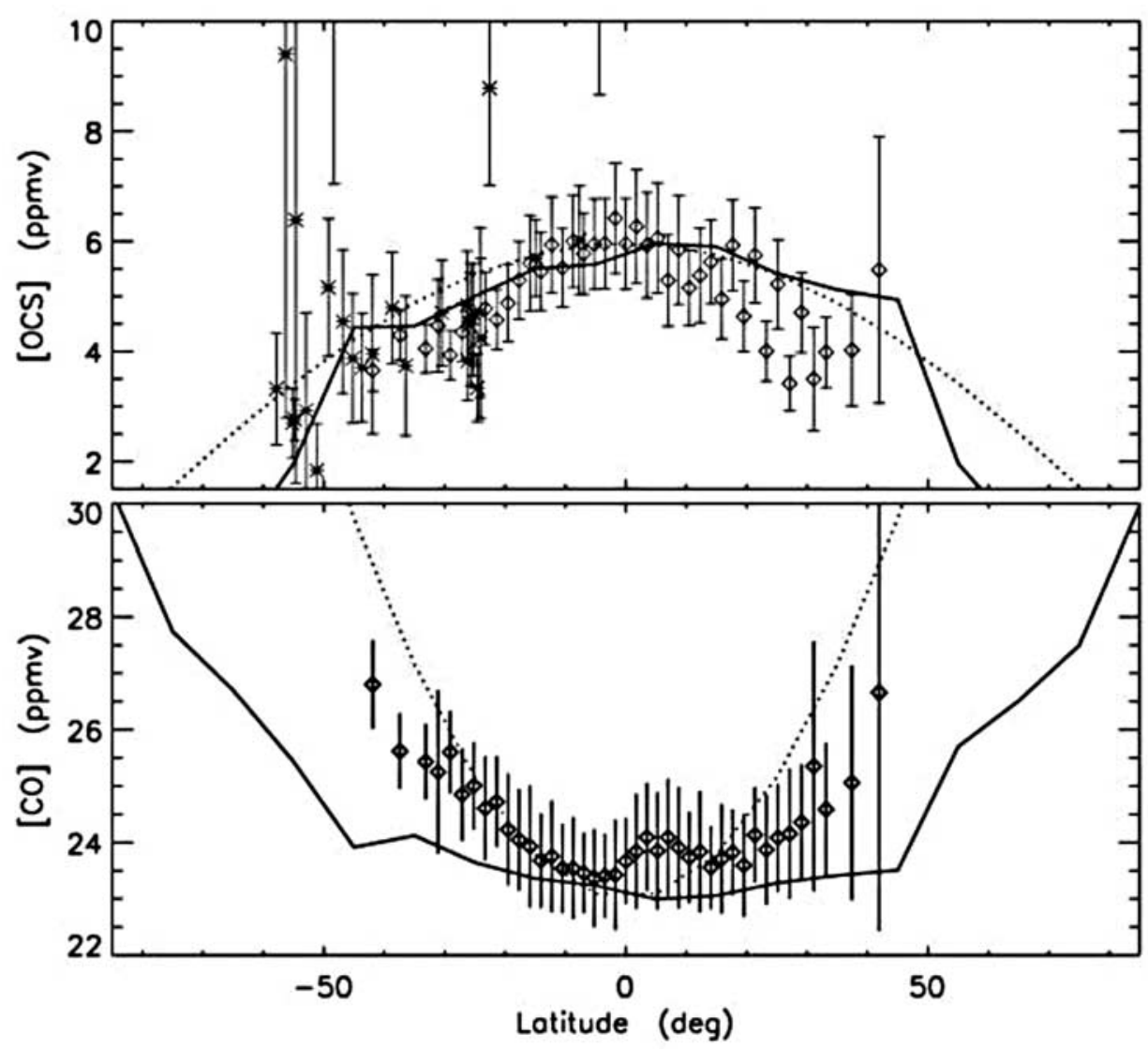

Figure 12. Same as Figure 11 for model F (see Table 3 and text).

the southern hemisphere. The purpose of this change is to make the Hadley cell narrower, so that we can sharpen the latitudinal gradient of OCS and CO. A measure of the latitudinal gradient is $\Delta \chi=\chi\left(0^{\circ}\right)-\chi\left(-60^{\circ}\right)$, where $\chi$ is the mixing ratio of OCS or CO. In model A, we have $\Delta[\mathrm{OCS}]=1.83 \mathrm{ppmv}$, as compared to the value of $1.65 \mathrm{ppmv}$ in the standard model. The corresponding values for $\Delta[\mathrm{CO}]$ are -1.84 and -1.51 ppmv. Therefore, the gradients of OCS and CO in model A are sharper than those in the standard model.

[31] Further accentuation of the gradients is achieved if we set $\mathrm{f}_{6}=3$ in model $\mathrm{B}$ (see Table 3 ). In model $\mathrm{C}$, we enhance the chemical reaction (R11) by a factor of 3. The chemistry change has a larger effect on OCS than CO. In model $\mathrm{D}$, we enhance the tropical stream function by a factor of 2 ; that is $f_{9}=2$. Horizontal diffusivity acts to remove the latitudinal gradient in the model. model $\mathrm{E}$ studies the effect of reducing $K_{y y}$ by a factor of 3 . This results in increases of the absolute values of $\Delta \chi$ in the model. This factor is increased to 10 in model $\mathrm{F}$, which represents the model with the greatest gradients studied so far. Figure 12 presents a comparison of data and model results for OCS and $\mathrm{CO}$ in model $\mathrm{F}$. The agreement is somewhat better than those in Figure 11, but crucial data at higher latitudes are lacking. The sharp edges in the model profiles are produced by advection and they could not be smoothed out owing to the low $K_{y y}$ in this model.
[32] Finally, in model $\mathrm{G}$ we test the relative importance of chemistry (R11) versus boundary conditions in determining $\Delta \chi$ in the model. This run is same as the standard model, except that tropospheric chemistry R11 $=0$. We note that in this case there remains a residual gradient due to downwelling of air at middle and high latitudes from the stratosphere (see Figure 8), where OCS (CO) is low (high).

\subsection{Is the Sum of OCS and CO a Constant?}

[33] The above discussion strongly suggests the possibility that the latitudinal variation in OCS and $\mathrm{CO}$ seen in Figure 11 is driven by the conversion of OCS to CO. In this case the sum of [OCS] and [CO] should be a constant. Figure 13 shows the data and model for $[\mathrm{OCS}]+[\mathrm{CO}]$, demonstrating that the sum is approximately a constant. Inspection of Table 3 suggests that $\Delta[\mathrm{OCS}]+\Delta[\mathrm{CO}]$ is roughly zero, further verifying that the changes are the result of OCS to $\mathrm{CO}$ conversion.

\section{Implications of the Model \\ 4.1. Sulfur Budget}

[34] Our model which is consistent with the observations suggests that the global rate of destruction of OCS is $\sim 23,000 \mathrm{Tg}-\mathrm{S} \mathrm{a}^{-1}$ (teragram of sulfur atom equivalence per year, i.e., $1 \mathrm{Tg}-\mathrm{S} \mathrm{a}^{-1}=3 \times 10^{10}$ moles a $\mathrm{a}^{-1}=2 \times 10^{34}$ OCS molecules a ${ }^{-1}$ ), a value that should be compared to the total volcanic source of $\sim 10 \mathrm{Tg}-\mathrm{S} \mathrm{a}{ }^{-1}$ for the Earth [see, 


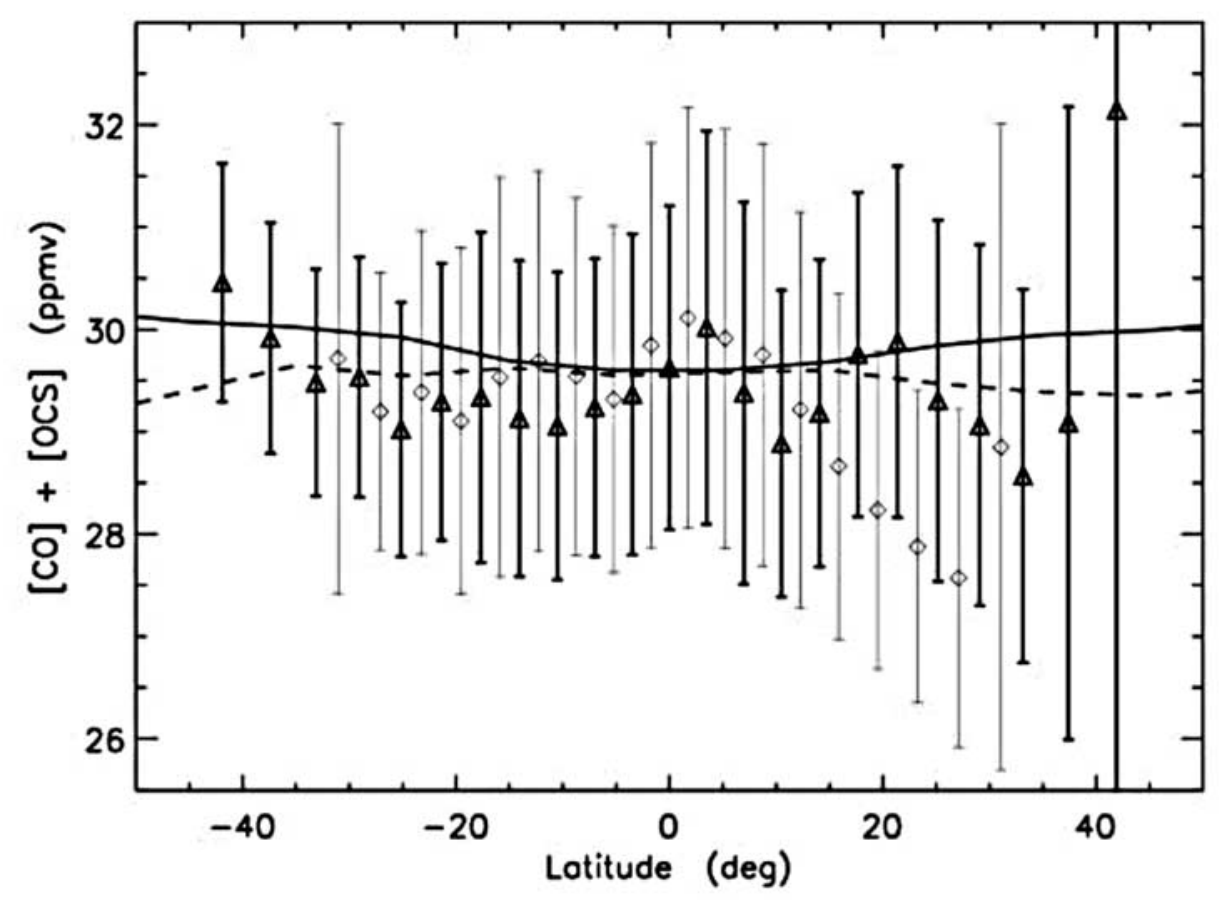

Figure 13. Comparison of model OCS $+\mathrm{CO}$ and data. Solid and dashed curves are for standard model and model F, respectively. Symbols are for two observations.

e.g., Seinfeld and Pandis, 1998]. The mean destruction rate is equivalent to $3.0 \times 10^{12}$ molecules $\mathrm{cm}^{-2} \mathrm{~s}^{-1}$, which is 43 times the corresponding rate of OCS destruction above the cloud tops (see Table 2). The middle atmosphere is a net sink for OCS. We argue that the large implied source of OCS is unlikely to be supplied by volcanic emission. For example, a large volcano like Pinatubo delivered about $10 \mathrm{Tg}-\mathrm{S}$ into the terrestrial stratosphere in 1991 [Bluth et al., 1992]. To produce fluxes consistent with our model would require $\sim 2300$ Pinatubo-sized eruptions per year. There is no geochemical or geological evidence in support of enhanced volcanic activities of this magnitude on Venus.

[35] It is more likely that OCS is produced by heterogeneous reactions on the surface from $C O$ and polysulfur $\left(S_{x}\right)$, or between $\mathrm{CO}$ and $\mathrm{CO}_{2}$ and surface minerals (e.g., pyrite), as discussed by Mills et al. [2007, section 3.2]. The reaction $\mathrm{S}_{2}+\mathrm{CO} \rightarrow \mathrm{OCS}+\mathrm{S}$ is favored by Hong and Fegley [1997] and Krasnopolsky [2007]. The CO ultimately comes from $\mathrm{CO}_{2}$ photolysis above the cloud tops and destruction of OCS in the middle atmosphere. Its mixing ratio remains fairly high, $\sim 10^{-5}$ near the surface [see Mills et al., 2007, Figure 3]. It is a challenge for the laboratory chemists to confirm and quantify these surface reactions.

[36] We shall argue that the OCS sink predicted by the model is a direct consequence of the circulation of the atmosphere and the observed vertical and horizontal gradients in OCS, independent of the details of the model. Referring to the middle box in Figure 8, the mass flux entering the box is $\varphi_{\text {in }}=1630 \times 10^{9} \mathrm{~kg} \mathrm{~s}^{-1}$. Thus, the $\mathrm{S}$ mass flux entering this box is $\varphi_{\text {in }} \times[\mathrm{OCS}]_{\text {in }} \times 32 / 44$. The mass fluxes out of this box are the upward flux at $50 \mathrm{~km}$ (where there is almost no OCS; see Figure 10) and the two horizontal fluxes $\varphi_{\text {out }}=410+390=800 \times 10^{9} \mathrm{~kg} \mathrm{~s}^{-1}$ at midlatitudes. Therefore, the $\mathrm{S}$ mass flux out of the center box is $\varphi_{\text {out }} \times[\mathrm{OCS}]_{\text {out }} \times 32 / 44$. Putting in approximate values from the data presented in Figure 11, $[\mathrm{OCS}]_{\text {in }}=$ 3.3 ppmv and $[\mathrm{OCS}]_{\mathrm{out}}=2.5 \mathrm{ppmv}$, we have the next sink for OCS equal to $76,000 \mathrm{Tg}-\mathrm{S} \mathrm{a}{ }^{-1}$, a value that is within a factor of 3 of our earlier number. The overestimate is not surprising, as we attribute the cause of the latitudinal gradient entirely to loss by $\mathrm{R} 11$, whereas comparison between model $\mathrm{G}$ and the standard model suggests that part of the gradient is caused by the upper boundary via the downward fluxes at middle to high latitudes.

\subsection{Previous Work on the Unidentified Reaction}

[37] Krasnopolsky and Pollack [1994] were the first to propose chemical destruction of OCS in the lower atmosphere of Venus. Krasnopolsky [2007] quantitatively modeled the following reactions for destroying OCS in the lower atmosphere:

$$
\begin{gathered}
\mathrm{H}_{2} \mathrm{SO}_{4} \rightarrow \mathrm{H}_{2} \mathrm{O}+\mathrm{SO}_{3} \\
\mathrm{SO}_{3}+\mathrm{OCS} \rightarrow \mathrm{CO}+(\mathrm{SO})_{2} \\
(\mathrm{SO})_{2}+\mathrm{OCS} \rightarrow \mathrm{CO}+\mathrm{SO}_{2}+\mathrm{S}_{2}
\end{gathered}
$$

net $\mathrm{H}_{2} \mathrm{SO}_{4}+2 \mathrm{OCS} \rightarrow \mathrm{H}_{2} \mathrm{O}+\mathrm{CO}_{2}+\mathrm{CO}+\mathrm{SO}_{2}+\mathrm{S}_{2}$

According to Krasnopolsky's [2007] estimate, $\left[\mathrm{SO}_{3}\right] \sim 5 \times$ $10^{13} \mathrm{~cm}^{-3}$ and $\mathrm{k}_{15} \sim 5 \times 10^{-23} \mathrm{~cm}^{3} \mathrm{~s}^{-1}$ at $30 \mathrm{~km}$, resulting 
in $\mathrm{L}_{15}=\mathrm{k}_{15}\left[\mathrm{SO}_{3}\right]=2.5 \times 10^{-9} \mathrm{~s}^{-1}$. This is of the same order of magnitude but somewhat smaller than $\mathrm{L}_{11}$ from (11). Similar estimate shows that the second Krasnopolsky reaction (16) yields an $\mathrm{L}_{16}=\mathrm{k}_{16}\left[(\mathrm{SO})_{2}\right]$ that is larger than $\mathrm{L}_{15}$. The combination of $\mathrm{L}_{15}$ and $\mathrm{L}_{16}$ is of the same magnitude as $\mathrm{L}_{11}$.

[38] A major weakness of this scheme is that reactions (15) and (16) are not based on laboratory studies. Laboratory experiments are urgently needed to verify or disprove these reactions. In view of these uncertainties associated with reactions (15) and (16), it is reasonable to propose alternatives. Three chemical schemes are discussed as follows.

\subsection{Other Possibilities for the Unidentified Reaction}

[39] We will briefly describe three additional possible mechanisms for the destruction of OCS on Venus. The first two are based on heterogeneous reactions on or in particles. The third mechanism is the photosensitized dissociation of OCS via the photochemistry of $\mathrm{S}_{\mathrm{x}}$.

[40] Chen et al. [2007] measured the rate of oxidation of OCS to $\mathrm{CO}_{2}$ on the surface of hematite. The uptake coefficient $(\gamma)$ lies in the range $10^{-7}$ to $10^{-11}$. The loss rate of OCS in the atmosphere can be estimated using the expression

$$
\mathrm{L}_{11}=1 / 4 \gamma \mathrm{vAN}_{\mathrm{a}}
$$

where $\mathrm{v}$ is the mean speed of the impacting molecule = $\sqrt{8 k T / \pi m}, \mathrm{~A}$ is the mean surface area of each hematite grain, and $\mathrm{N}_{\mathrm{a}}$ is number density of hematite grains. Since $\mathrm{L}_{11} \sim 10^{-8} \mathrm{~s}^{-1}$ and $\mathrm{v} \sim 10^{4} \mathrm{~cm} \mathrm{~s}^{-1}, \mathrm{AN}_{\mathrm{a}}$ must be $\sim 10^{-5}$ to $10^{-1} \mathrm{~cm}^{2} \mathrm{~cm}^{-3}$. For comparison, $\mathrm{AN}_{\mathrm{a}}$ is $\sim 3 \times 10^{-6}$ in the terrestrial stratosphere for dust after the eruption of the El Chichon volcano [Michelangeli et al., 1991]. Therefore, while not ruled out, this reaction is probably too slow to have an impact for the destruction of OCS in lower atmosphere.

[41] Dalleska et al. [2000] measured the rate coefficient for the oxidation of OCS by $\mathrm{H}_{2} \mathrm{O}_{2}$ in sulfuric acid solution. While the abundance of sulfuric acid is high on Venus, the limiting chemical may be $\mathrm{H}_{2} \mathrm{O}_{2}$, which is produced in small abundance at 80 to $90 \mathrm{~km}$ (see Figure 3). Thus, unless we have evidence otherwise, we consider this mechanism unlikely.

[42] The third proposal is the photosensitized dissociation of OCS via the photochemistry of $\mathrm{S}_{\mathrm{x}}$. The idea is based on with analogy with the photosensitized dissociation of $\mathrm{H}_{2} \mathrm{O}$ in the troposphere of the Earth:

$$
\begin{gathered}
\mathrm{O}_{3}+\mathrm{h} \nu \rightarrow \mathrm{O}_{2}+\mathrm{O}\left({ }^{1} \mathrm{D}\right) \\
\mathrm{H}_{2} \mathrm{O}+\mathrm{O}\left({ }^{1} \mathrm{D}\right) \rightarrow \mathrm{OH}+\mathrm{OH}
\end{gathered}
$$

In this case, the dissociation of $\mathrm{H}_{2} \mathrm{O}$ could not occur directly because the short-wavelength $\mathrm{UV}$ photons required to dissociate $\mathrm{H}_{2} \mathrm{O}(\lambda<200 \mathrm{~nm})$ are absorbed by $\mathrm{O}_{2}$ and $\mathrm{O}_{3}$ in the stratosphere. However, the long-wavelength UV photons $(\lambda>310 \mathrm{~nm})$ can penetrate to the troposphere and photolyze $\mathrm{O}_{3}$ to produce $\mathrm{O}\left({ }^{1} \mathrm{D}\right)$, which then reacts with $\mathrm{H}_{2} \mathrm{O}$ [see Sander et al., 2006; Yung and DeMore, 1999, chapter 10]. We argue that, by analogy with (19) and (20) on Earth, the photochemistry of $S_{x}$ could lead to photosensitized dissociation of OCS using long-wavelength photons that can penetrate to the lower atmosphere of Venus. The details of the $\mathrm{S}_{\mathrm{x}}$ scheme are referred to in Appendix A.

[43] The key reaction in this case is the reaction (R7) in Appendix A, OCS $+\mathrm{S} \rightarrow \mathrm{CO}+\mathrm{S}_{2}$. This reaction was considered by Prinn [1975] and Krasnopolsky [2007], and was measured by $\mathrm{Lu}$ et al. [2006] in the temperature range $298-985 \mathrm{~K}$. This is adequate for our modeling. The crucial requirement is that the number density of $\mathrm{S}$ atoms at $30 \mathrm{~km}$ must be $\sim 10^{5} \mathrm{~cm}^{-3}$. Without a source of $\mathrm{S}$ atoms from the $\mathrm{S}_{\mathrm{x}}$ photochemistry in Appendix A, Krasnopolsky [2007] predicts $[\mathrm{S}] \sim 10 \mathrm{~cm}^{-3}$, which is too low to have impact on the OCS distribution.

\subsection{Testable Hypotheses}

[44] The nature of the unidentified reaction in the lower atmosphere of Venus can only be resolved with better atmospheric measurements and laboratory experiments. Therefore, the proposed chemical schemes constitute testable hypotheses that are useful for guiding future experiments.

\subsubsection{Krasnopolsky's Scheme}

[45] Reactions (15) and (16) must be demonstrated in the laboratory. The existence of $\mathrm{SO}_{3}$ follows from the thermal decomposition of $\mathrm{H}_{2} \mathrm{SO}_{4}$, but the existence of $(\mathrm{SO})_{2}$ is less obvious. Both must be measured in the atmosphere of Venus.

\subsubsection{Heterogeneous Reactions}

[46] The two heterogeneous reactions discussed in section 4.3 were studied at room temperature. It is conceivable that they could be faster at higher temperatures. Also, there may be other types of heterogeneous reactions not considered here. A thorough laboratory search is needed.

\subsubsection{Photosensitized Dissociation}

[47] A comprehensive study of the UV radiation and $S_{x}$ photochemistry in the lower atmosphere is needed to make a realistic assessment of the concentration of $\mathrm{S}$ atoms at $30 \mathrm{~km}$. Measurements of sulfur speciation as well as UV irradiance in the lower atmosphere would be valuable.

\section{Concluding Remarks}

[48] A simple two-dimensional chemistry and transport (2-D CTM) model is used to study the spatial distributions of OCS and CO in the lower atmosphere of Venus. The residual circulation and horizontal eddy diffusivities are derived from winds from Lee et al.'s [2007] general circulation model. The Hadley circulation provides rapid transport in the lower atmosphere of Venus. Mixing between the surface and the cloud tops occurs in as short as 10 years, which is significantly shorter than previous estimates of this time constant. The results for the latitude-altitude distributions of OCS and CO from our 2-D CTM are compared to recent observations (see Figure 11). A total of eight models were studied to test the sensitivity of model results to input parameters, as summarized in Table 3. High-latitude data for OCS and CO are urgently needed to distinguish between the current models, shown in Figure 11 (standard model) and Figure 12 (model F), or a more realistic 


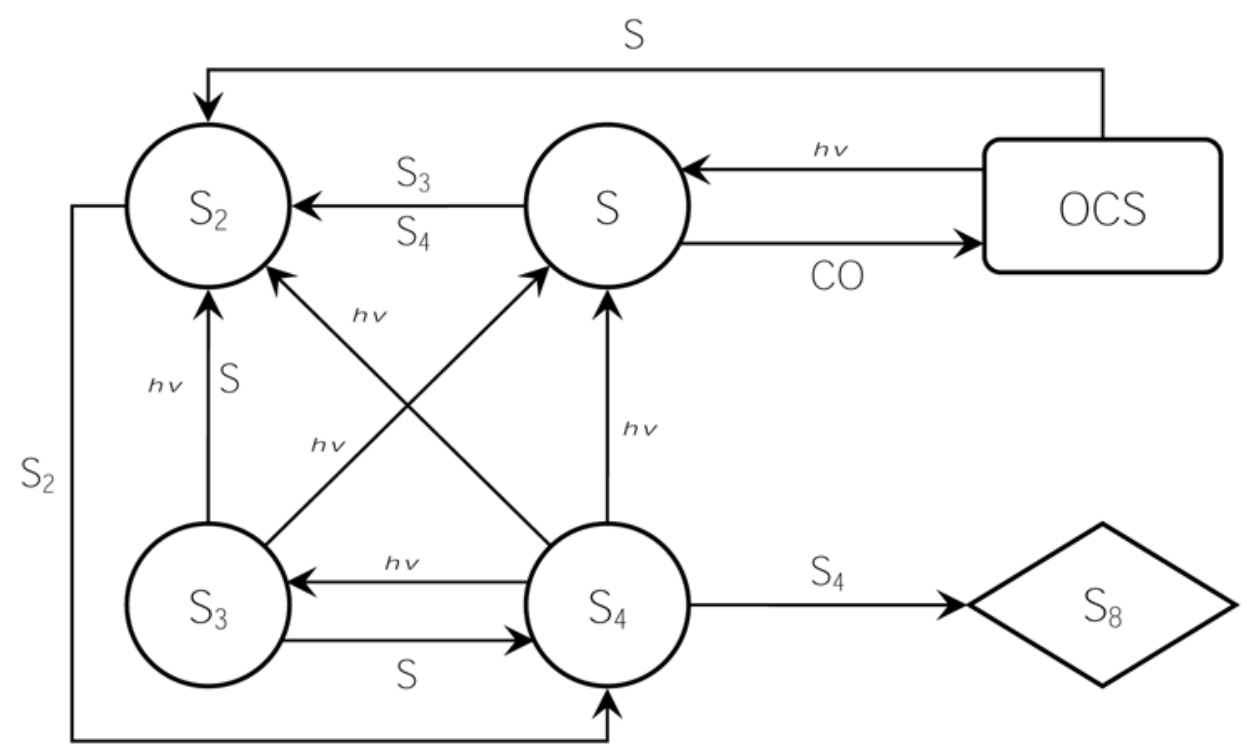

Figure A1. Schematic diagram illustrating the $S_{n}$ chemistry in the lower atmosphere.

CTM. Further work is also required on the GCM used in this work in order to improve the simulated circulation in our model so that we may better constrain the effects of the unknown reaction(s).

[49] There is compelling evidence for an unidentified chemical reaction that destroys OCS in the lower atmosphere of Venus around $30 \mathrm{~km}$. There is strong evidence that this unidentified reaction converts OCS to $\mathrm{CO}$ (but not to $\mathrm{CO}_{2}$ ), as both data and model suggest that the sum of OCS and CO is roughly a constant (see Figure 13 and section 3.3). A major implication of the model is that the total loss rate of OCS in the lower atmosphere is about $23,000 \mathrm{Tg}-\mathrm{S} \mathrm{a}{ }^{-1}$. This is a robust result that does not depend on the details of the 2-D CTM. The value can be derived from heuristic arguments based on the strength of the Hadley circulation and observed chemical gradients (see section 4.1).

[50] The nature of the unidentified reaction remains controversial. A survey of recent literature and this work reveal three testable hypotheses: (1) Krasnopolsky's [2007] reactions of OCS with $\mathrm{SO}_{3}$ and $(\mathrm{SO})_{2}$ (see section 4.2), (2) heterogeneous reactions on hermatite or sulfuric acid particles (see section 4.3), and (3) photosensitized dissociation of OCS driven by absorption of soft UV by $S_{x}$ (see section 4.3 and Appendix A). New laboratory experiments and observations are urgently needed to prove or disprove the proposed hypotheses (see section 4.4). We note that if the last speculative chemistry were confirmed, there would important implications for the modeling of the evolution of the terrestrial atmosphere [Kasting et al., 1989; Farquhar et al., 2002].

\section{Appendix A: Hypothesis of an Innovative Chemical Cycle}

[51] In order to account for the additional loss of OCS below the cloud tops (see Figure 10 (right)), we propose an innovative photosensitized dissociation of OCS driven by photolysis of $S_{n}$ using photons at long wavelengths that are able to penetrate through the clouds

$$
\begin{gathered}
2\left[\mathrm{~S}_{3}+\mathrm{h} \nu \rightarrow \mathrm{S}_{2}+\mathrm{S}\right] \quad(\mathrm{R} 3) \\
\mathrm{S}_{4}+\mathrm{h} \nu \rightarrow \mathrm{S}_{3}+\mathrm{S} \quad(\mathrm{R} 5) \\
\mathrm{S}_{2}+\mathrm{S}+\mathrm{M} \rightarrow \mathrm{S}_{3}+\mathrm{M} \quad(\mathrm{R} 8) \\
\mathrm{S}_{2}+\mathrm{S}_{2}+\mathrm{M} \rightarrow \mathrm{S}_{4}+\mathrm{M} \quad(\mathrm{R} 9) \\
2\left[\mathrm{OCS}+\mathrm{S} \rightarrow \mathrm{CO}+\mathrm{S}_{2}\right] \quad(\mathrm{R} 7) \\
\multicolumn{2}{l}{\text { net } 2 \mathrm{OCS} \rightarrow 2 \mathrm{CO}+\mathrm{S}_{2}}
\end{gathered}
$$

The details of this innovative chemistry are summarized in Table A1 and shown in Figure A1. The reactions $\left(R_{n}\right)$ refer to the reaction set listed in Table A1. Note that the scheme has the following characteristics: (1) photolysis at UV wavelengths releases $\mathrm{S}$ from OCS, (2) S reacts with OCS to form $S_{2}$ and subsequent reactions produces $S_{n}$, (3) photolysis of $S_{n}$ occurs at near UV and longer wavelengths, producing $S$, and (4) cycle repeats via characteristic 2.

[52] The net result is summarized by (9). This scheme is known as photosensitized dissociation (for a discussion of this process see, e.g., Yung et al. [1984, section 2]). The rate coefficient for the key reaction (R7) has recently been measured in the temperature range of $298-985 \mathrm{~K}$ by $L u$ et al. [2006] and their expression is given in Table 1. At $500 \mathrm{~K}, \mathrm{k}_{7}=5.41 \times 10^{-14} \mathrm{~cm}^{3} \mathrm{~s}^{-1}$ is much smaller than the value $5.30 \times 10^{-13} \mathrm{~cm}^{3} \mathrm{~s}^{-1}$ used by Prinn [1975] but is close to the value $6.29 \times 10^{-14} \mathrm{~cm}^{3} \mathrm{~s}^{-1}$ estimated by Krasnopolsky [2007]. We must emphasize the speculative nature of the proposed chemistry. There remain major gaps in our knowledge of the chemistry of $S_{n}$ in Table A1 and Figure A1; new laboratory studies are needed to close the gaps.

[53] In a crude model we have for $\mathrm{S}_{\mathrm{n}}$ around $30 \mathrm{~km}$ the following concentrations, $[\mathrm{S}]=1 \times 10^{5} \mathrm{~cm}^{-3},\left[\mathrm{~S}_{2}\right]=2 \times$ $10^{8} \mathrm{~cm}^{-3},\left[\mathrm{~S}_{3}\right]=7 \times 10^{9} \mathrm{~cm}^{-3},\left[\mathrm{~S}_{4}\right]=7 \times 10^{9} \mathrm{~cm}^{-3},\left[\mathrm{~S}_{8}\right]=$ $4 \times 10^{14} \mathrm{~cm}^{-3}$. We do not go beyond $\mathrm{S}_{8}$, which has no atmospheric sink (and therefore a large concentration). It is 
Table A1. List of Reactions Related to the Chemistry of $S_{n}$ as Shown in Figure A1

\begin{tabular}{|c|c|c|c|}
\hline & Reaction & Rate Coefficient ${ }^{\mathrm{a}}$ & Reference \\
\hline (R1) & $\mathrm{OCS}+\mathrm{h} \nu \rightarrow \mathrm{CO}+\mathrm{S}$ & $\mathrm{J}_{1}=3.81 \times 10^{-5}$ & Molina et al. [1981] \\
\hline (R2) & $\mathrm{S}_{2}+\mathrm{h} \nu \rightarrow \mathrm{S}+\mathrm{S}$ & $\mathrm{J}_{2}=9.93 \times 10^{-3}$ & Moses et al. [2002, and references therein] \\
\hline (R3) & $\mathrm{S}_{3}+\mathrm{h} \nu \rightarrow \mathrm{S}_{2}+\mathrm{S}$ & $\mathrm{J}_{3}=1.15$ & Moses et al. [2002, and references therein] \\
\hline (R4) & $\mathrm{S}_{4}+\mathrm{h} \nu \rightarrow \mathrm{S}_{2}+\mathrm{S}_{2}$ & $\mathrm{~J}_{4}=1.07 \times 10^{-1}$ & $\begin{array}{c}\text { Moses et al. [2002, and references therein]; } \\
\text { Branching ratio estimated }\end{array}$ \\
\hline (R5) & $\mathrm{S}_{4}+\mathrm{h} \nu \rightarrow \mathrm{S}_{3}+\mathrm{S}$ & $\mathrm{J}_{5}=1.07 \times 10^{-1}$ & $\begin{array}{c}\text { Moses et al. }[2002, \text { and references therein]; } \\
\text { Branching ratio estimated }\end{array}$ \\
\hline (R7) & $\mathrm{OCS}+\mathrm{S} \rightarrow \mathrm{CO}+\mathrm{S}_{2}$ & $\mathrm{k}_{7}=6.63 \times 10^{-20} \mathrm{~T}^{2.57} \mathrm{e}^{-1180 / \mathrm{T}}$ & Lu et al. $[2006]$ \\
\hline (R8) & $\mathrm{S}_{2}+\mathrm{S}+\mathrm{M} \rightarrow \mathrm{S}_{3}+\mathrm{M}$ & $\begin{aligned} \mathrm{k}_{8}(0) & =1.00 \times 10^{-30} \\
\mathrm{k}_{8}(\infty) & =3.00 \times 10^{-11}\end{aligned}$ & Mills [1998] \\
\hline (R9) & $\mathrm{S}_{2}+\mathrm{S}_{2}+\mathrm{M} \rightarrow \mathrm{S}_{4}+\mathrm{M}$ & $\begin{array}{l}\mathrm{k}_{9}(0)=2.20 \times 10^{-29} \\
\mathrm{k}_{9}(\infty)=1.00 \times 10^{-11}\end{array}$ & Mills [1998] \\
\hline (R10) & $\mathrm{S}_{4}+\mathrm{S}_{4}+\mathrm{M} \rightarrow \mathrm{S}_{8}+\mathrm{M}$ & $\begin{array}{l}\mathrm{k}_{10}(0)=1.00 \times 10^{-30} \\
\mathrm{k}_{10}(\infty)=3.00 \times 10^{-11}\end{array}$ & Mills [1998] \\
\hline (R11) & $\mathrm{S}_{3}+\mathrm{S} \rightarrow \mathrm{S}_{2}+\mathrm{S}_{2}$ & $\mathrm{k}_{11}=3.00 \times 10^{-11}$ & Mills [1998] \\
\hline (R12) & $\mathrm{S}_{4}+\mathrm{S} \rightarrow \mathrm{S}_{3}+\mathrm{S}_{2}$ & $\mathrm{k}_{11}=3.00 \times 10^{-11}$ & Mills [1998] \\
\hline \multirow[t]{2}{*}{ (R13) } & $\mathrm{CO}+\mathrm{S}+\mathrm{M} \rightarrow \mathrm{OCS}+\mathrm{M}$ & $\mathrm{k}_{13}(0)=4.00 \times 10^{-36} \mathrm{e}^{-1940 / \mathrm{T}}$ & $\begin{array}{l}\text { Mills [1998]; Estimated on the basis } \\
\text { of analogy with } \mathrm{O}+\mathrm{CO}+\mathrm{M} \rightarrow \\
\qquad \mathrm{CO}_{2}+\mathrm{M}\end{array}$ \\
\hline & & $\mathrm{k}_{13}(\infty)=1.00 \times 10^{-15}$ & \\
\hline
\end{tabular}

${ }^{a}$ The photolytic coefficients are given for a diurnally averaged model at $30^{\circ} \mathrm{N}$ at the top of the atmosphere $\left(\mathrm{s}^{-1}\right)$. Two-body and three-body rate coefficients are given in units of $\mathrm{cm}^{3} \mathrm{~s}^{-1}$ and $\mathrm{cm}^{6} \mathrm{~s}^{-1}$, respectively; $\mathrm{k}(0)$ and $\mathrm{k}(\infty)$ refer to rate coefficient in the low and high pressure limit, respectively.

transported to the surface, where surface reactions will recombine the sulfur and $\mathrm{CO}$ to form OCS, thus completing the cycling of OCS. Note that $\mathrm{S}_{3}$ has been tentatively identified by UV data from Venera 14 , and $S_{x}$ is a leading candidate for the unidentified UV and blue absorber [see Mills et al., 2007, sections 3 and 6]. The amount quoted for $\mathrm{S}_{3}$ by Maiorov et al. [2005] is 0.03 to $0.1 \mathrm{ppb}$. Bertaux et al. [1986] reported 5 to 25 ppmv of $S_{8}$ from 25 to $45 \mathrm{~km}$ from analysis of UV data obtained by Venera 11 and 12 . Note that $10 \mathrm{ppmv}$ of $\mathrm{S}_{8}$ at $30 \mathrm{~km}$ corresponds to $\left[\mathrm{S}_{8}\right] \sim 1 \times 10^{15} \mathrm{~cm}^{-3}$, which is of the same order magnitude as what is needed in the model. However, the authors concluded that such values might be 2 orders of magnitudes too high. One resolution of the conflict is that the UV absorption in the lower atmosphere of Venus may not be homogeneous, creating gaps through which UV may penetrate to much deeper levels than an average model would predict.

[54] Acknowledgments. We thank K. Baines, P. Drossart, J. Moses, C. Parkinson, V. Natraj, and X. Zhang for helpful discussions, D. Crisp for providing UV absorber profiles, and K. F. Li, D. Yang, and X. Zhang for assistance in preparing the manuscript. Special thanks are due to W. B. DeMore for a critical discussion of sulfur chemistry and S. Lebonnois and three anonymous referees for raising fundamental issues the resolution of which led to a much better paper. This research was supported by NASA grant NNX07AI63G to the California Institute of Technology. M. Liang was supported by NSC 97-2628-M-001-001 grant to Academia Sinica

\section{References}

Arakawa, A., and V. R. Lamb (1977), Computational design of the basic dynamical processes of the UCLA general circulation model, Methods Comput. Phys., 17, 173-265.

Bertaux, J. L., et al. (1986), Active spectrometry of the ultraviolet-absorption within the Venus atmosphere, Sov. Astron. Lett., 12, 33-37, Engl. Transl.

Bertaux, J. L., et al. (2007), A warm layer in Venus' cryosphere and highlatitude measurements of $\mathrm{HF}, \mathrm{HCl}, \mathrm{H} 2 \mathrm{O}$, and $\mathrm{HDO}$, Nature, 450, 646649, doi:10.1038/nature05974.

Bézard, B., et al. (1993), The abundance of sulfur-dioxide below the clouds of Venus, Geophys. Res. Lett., 20, 1587-1590, doi:10.1029/93GL01338.

Bluth, G. J. S., et al. (1992), Global tracking of the $\mathrm{SO}_{2}$ clouds from the June, 1991 Mount-Pinatubo eruptions, Geophys. Res. Lett., 19, 151-154, doi:10.1029/91GL02792.

Chen, H., et al. (2007), Heterogeneous uptake of carbonyl sulfide on hematite and hematite-NaCl mixtures, Environ. Sci. Technol., 41, 6484-6490, doi:10.1021/es070717n.
Crisp, D. (1986), Radiative forcing of the Venus mesosphere: 1. Solar fluxes and heating rates, Icarus, 67, 484-514, doi:10.1016/0019. 1035(86)90126-0.

Cullen, M. J. P. (1993), The unified forecast climate model, Meteorol. Mag., $122,81-94$.

Dalleska, N. F., A. J. Colussi, A. M. Hyldahl, and M. R. Hoffmann (2000), Rates and mechanism of carbonyl sulfide oxidation by peroxides in concentrated sulfuric acid, J. Phys. Chem. A, 104, 10,794-10,796, doi:10.1021/jp002333o.

Farquhar, J., B. A. Wing, K. D. McKeegan, J. W. Harris, P. Cartigny, and M. H. Thiemens (2002), Mass-independent sulfur of inclusions in diamond and sulfur recycling on early earth, Science, 298, 2369-2372, doi: $10.1126 /$ science. 1078617 .

Fegley, B., Jr., G. Klingelhofer, and L. Lodders (1997), Geochemistry of surface-atmosphere interactions on Venus, in Venus II: Geology, Geophysics, Atmosphere, and Solar Wind Environment, edited by S. W. Bougher et al., pp. 591-636, Univ. of Ariz. Press, Tucson.

Hall, T. M., and D. W. Waugh (1997), Timescales for the stratospheric circulation derived from tracers, J. Geophys. Res., 102, 8991-9001, doi:10.1029/96JD03713.

Herrnstein, A., and T. E. Dowling (2007), Effects of topography on the spin-up of a Venus atmospheric model, J. Geophys. Res., 112, E04S08, doi:10.1029/2006JE002804.

Hollingsworth, J. L., et al. (2007), A simple-physics global circulation model for Venus: Sensitivity assessments of atmospheric superrotation, Geophys. Res. Lett., 34, L05202, doi:10.1029/2006GL028567.

Hong, Y., and B. Fegley Jr. (1997), Formation of carbonyl sulfide (OCS) from carbon monoxide and sulfur vapor and applications to Venus, Icarus, 130, 495-504, doi:10.1006/icar.1997.5824

Jiang, X., et al. (2004), Quasi-biennial oscillation and quasi-biennial oscillation-annual beat in the tropical total column ozone: A twodimensional model simulation, J. Geophys. Res., 109, D16305, doi:10.1029/2003JD004377.

Juckes, M. N., I. N. James, and M. Blackburn (1994), The influence of Antarctica on the momentum budget of the southern extratropics, Q. J.R. Meteorol. Soc., 120, 1017-1044, doi:10.1002/qj.49712051811.

Kasting, J. F., K. J. Zahnle, J. P. Pinto, and A. T. Young (1989), Sulfur, ultraviolet-radiation, and the early evolution of life, Origins Life Evol. Biosphere, 19, 95-108, doi:10.1007/BF01808144.

Krasnopolsky, V. A. (2007), Chemical kinetic model for the lower atmosphere of Venus, Icarus, 191, 25-37, doi:10.1016/j.icarus.2007.04.028.

Krasnopolsky, V. A. (2008), High-resolution spectroscopy of Venus: Detection of OCS, upper limit to $\mathrm{H} 2 \mathrm{~S}$, and latitudinal variations of $\mathrm{CO}$ and $\mathrm{HF}$ in the upper cloud layer, Icarus, 197, 377-385, doi:10.1016/ j.icarus.2008.05.020.

Krasnopolsky, V. A., and J. B. Pollack (1994), H2O-H2SO4 system in Venus clouds and $\mathrm{OCS}, \mathrm{CO}$, and $\mathrm{H} 2 \mathrm{SO} 4$ profiles in Venus troposphere, Icarus, 109, 58-78, doi:10.1006/icar.1994.1077.

Lebonnois, S., D. Toublanc, F. Hourdin, and P. Rannou (2001), Seasonal variations of Titan's atmospheric composition, Icarus, 152, 384-406, doi:10.1006/icar.2001.6632. 
Lee, C., S. R. Lewis, and P. L. Read (2007), Superrotation in a Venus general circulation model, J. Geophys. Res., 112, E04S11, doi:10.1029/ 2006JE002874.

Lewis, J. S. (1970), Venus: Atmospheric and lithospheric composition, Earth Planet. Sci. Lett., 10, 73 -80, doi:10.1016/0012-821X(70)90066-X.

Liang, M.-C., and Y. L. Yung (2007), Sources of the oxygen isotopic anomaly in atmospheric $\mathrm{N}_{2} \mathrm{O}, J$. Geophys. Res., 112, D13307, doi:10.1029/2006JD007876.

Liang, M. C., et al. (2005), Meridional transport in the stratosphere of Jupiter, Astrophys. J., 635, L177-L180, doi:10.1086/499624.

Liang, M. C., et al. (2006), Isotopic composition of oxygen of stratospheric ozone, J. Geophys. Res., 111, D02302, doi:10.1029/2005JD006342.

Limaye, S. S. (2007), Venus atmospheric circulation: Known and unknown, J. Geophys. Res., 112, E04S09, doi:10.1029/2006JE002814.

Lu, C. W., Y. J. Wu, Y. P. Lee, R. S. Zhu, and M. C. Lin (2006), Experimental and theoretical investigation of rate coefficients of the reaction $\mathrm{S}$ (P-3)+OCS in the temperature range of 298-985 K, J. Chem. Phys., 125(16), 164329, doi:10.1063/1.2357739.

Maiorov, B. S., et al. (2005), A new analysis of the spectra obtained by the VENERA missions in the Venusian atmosphere: I. The analysis of the data received from the VENERA-11 probe at altitudes below $37 \mathrm{~km}$ in the 0.44-0.66 $\mu \mathrm{m}$ wavelength range, Sol. Syst. Res., 39, 267-282, doi:10.1007/s11208-005-0042-1.

Marcq, E., B. Bézard, T. Encrenaz, and M. Birlan (2005), Latitudinal variations of $\mathrm{CO}$ and $\mathrm{OCS}$ in the lower atmosphere of Venus from nearinfrared nightside spectro-imaging, Icarus, 179, 375-386, doi:10.1016/ j.icarus.2005.06.018

Marcq, E., T. Encrenaz, B. Bézard, and M. Birlan (2006), Remote sensing of Venus' lower atmosphere from ground-based IR spectroscopy: Latitudinal and vertical distribution of minor species, Planet. Space Sci., 54 , 1360-1370, doi:10.1016/j.pss.2006.04.024

Marcq, E., B. Bézard, P. Drossart, G. Piccioni, J. M. Reess, and F. Henry (2008), A latitudinal survey of $\mathrm{CO}, \mathrm{OCS}, \mathrm{H}_{2} \mathrm{O}$, and $\mathrm{SO}_{2}$ in the lower atmosphere of Venus: Spectroscopic studies using VIRTIS-H, J. Geophys. Res., 113, E00B07, doi:10.1029/2008JE003074.

Michelangeli, D. V., M. Allen, and Y. L. Yung (1991), Heterogeneous reactions with $\mathrm{NaCl}$ in the El Chichon volcanic aerosols, Geophys. Res. Lett., 18, 673-676, doi:10.1029/91GL00547.

Mills, F. P. (1998), I. Observations and photochemical modeling of the Venus middle atmosphere. II. Thermal infrared spectroscopy of Europa and Callisto, Ph.D. thesis, Calif. Inst. of Technol., Pasadena, Calif.

Mills, F. P., and M. Allen (2007), A review of selected issues concerning the chemistry in Venus' middle atmosphere, Planet. Space Sci., 55 1729-1740, doi:10.1016/j.pss.2007.01.012.

Mills, F. P., L. W. Esposito, and Y. L. Yung (2007), Atmospheric composition, chemistry, and clouds, in Exploring Venus as a Terrestrial Planet, Geophys. Monogr. Ser., vol. 176, edited by L. W. Esposito, E. Stofan, and T. Cravens, pp. 73-100, AGU, Washington, D. C.

Molina, L. T., J. J. Lamb, and M. J. Molina (1981), Temperature-dependen UV absorption cross-sections for carbonyl sulfide, Geophys. Res. Lett., 8, 1008-1011, doi:10.1029/GL008i009p01008

Moses, J. I., M. Y. Zolotov, and B. Fegley (2002), Photochemistry of a volcanically driven atmosphere on Io: Sulfur and oxygen species from a pele-type eruption, Icarus, 156, 76-106, doi:10.1006/icar.2001.6758.

Peixoto, J. P., and A. H. Oort (1992), Physics of Climate, 520 pp., Am. Inst. of Phys., New York.
Pernice, H., et al. (2004), Laboratory evidence for a key intermediate in the Venus atmosphere: Peroxychloroformyl radical, Proc. Natl. Acad. Sci. U. S. A., 101, 14,007-14,010, doi:10.1073/pnas.0405501101.

Pollack, J. B., et al. (1993), Near-infrared light from Venus' nightside: A spectroscopic analysis, Icarus, 103, 1-42, doi:10.1006/icar.1993.1055.

Prinn, R. G. (1975), Venus: Chemical and dynamical processes in the stratosphere and mesosphere, J. Atmos. Sci., 32, 1237-1247, doi:10.1175/1520-0469(1975)032<1237:VCADPI > 2.0.CO;2.

Prinn, R. G. (1978), Venus: Chemistry of the lower atmosphere prior to the Pioneer Venus mission, Geophys. Res. Lett., 5, 973-976, doi:10.1029/ GL005i011p00973.

Prinn, R. G. (1979), On the possible roles of gaseous sulfur and sulfanes in the atmosphere of Venus, Geophys. Res. Lett., 6, 807-810, doi:10.1029/ GL006i010p00807.

Sander, S. P., et al. (2006), Chemical kinetics and photochemical data for use in stratospheric modeling evaluation number 15, JPL Publ. 06-2, $523 \mathrm{pp}$.

Schubert, G. (1983), General circulation and the dynamical state of the Venus atmosphere, in Venus, edited by D. M. Hunten et al., pp. $681-$ 765, The Univ. of Ariz. Press, Tuscon.

Seinfeld, J. H., and S. N. Pandis (1998), Atmospheric Chemistry and Physics: From Air Pollution to Global Change, John Wiley, New York. Shia, R. L., Y. L. Yung, M. Allen, R. W. Zurek, and D. Crisp (1989), Sensitivity study of advection and diffusion coefficients in a twodimensional stratospheric model using excess C-14 data, J. Geophys. Res., 94, 18,467-18,484, doi:10.1029/JD094iD15p18467.

Toon, O. B., R. P. Turco, and J. B. Pollack (1982), The ultraviolet absorber on Venus: Amorphous sulfur, Icarus, 51, 358-373, doi:10.1016/0019. 1035(82)90089-6.

von Zahn, U., S. Kumar, H. Niemann, and R. G. Prinn (1983), Composition of the Venus atmosphere, in Venus, edited by D. M. Hunten et al., pp. 299 430, Univ. of Ariz. Press, Tucson.

Yamamoto, M., and M. Takahashi (2003), Superrotation and equatorial waves in a T21 Venus-like AGCM, Geophys. Res. Lett., 30(9), 1449 doi:10.1029/2003GL016924.

Yung, Y. L., and W. B. DeMore (1982), Photochemistry of the stratosphere of Venus: Implications for atmospheric evolution, Icarus, 51, 199-247, doi:10.1016/0019-1035(82)90080-X.

Yung, Y. L., and W. B. DeMore (1999), Photochemistry of Planetary Atmospheres, Oxford Univ. Press, New York.

Yung, Y. L., M. Allen, and J. P. Pinto (1984), Photochemistry of the atmosphere of Titan: Comparison between model and observations, Astrophys. J. Suppl. Ser., 55(3), 465-506, doi:10.1086/190963.

B. Bézard and E. Marcq, LESIA, Observatoire de Paris, Bâtiment 18, pièce 111, F-92195 Meudon CEDEX, France.

X. Jiang, Department of Earth and Atmospheric Sciences, University of Houston, Houston, TX 77004, USA.

C. Lee, R. L. Shia, and Y. L. Yung, Division of Geological and Planetary Sciences, California Institute of Technology, Pasadena, CA 91125, USA. (yly@gps.caltech.edu)

M. C. Liang, Research Center for Environmental Changes, Academia Sinica, 128 Academia Road, Section 2, Taipei 115, Taiwan. 